\title{
ENCONTRANDO OS FEMINISMOS LATINO-AMERICANOS E CARIBENHOS
}

\author{
SONIA E. ALVAREZ \\ University of California, Santa Cruz \\ ELISABETH JAY FRIEDMAN \\ Barnard College, Columbia University \\ ERICKA BECKMAN \\ Stanford University \\ MAYLEI BLACKWELL \\ Loyola Marymount University, Los Angeles
}

NORMA STOLTZ CHINCHILLA

California State University, Long Beach

\author{
NATHALIE LEBON \\ Randolph-Macon College \\ MARYSA NAVARRO \\ Dartmouth College \\ MARCELA RÍOS TOBAR
}

Centro de Estudios de la Mujer (CEM)

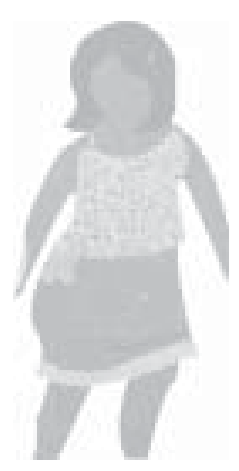

Resumo: Este artigo examina os Encontros Latino-Americanos e do Caribe como espaços críticos transnacionais onde se re-imagina a política dos feminismos na região. Enfocando o Oitavo desses Encontros, realizado em Juan Dolio, República Dominicana, em 1999, analisamos os principais debates politicos e filosóficos que surgiram durante 20 anos de Encontros: (1) mudanças nas concepções de 'autonomia' do movimento e na relação dos feminismos com o movimento de mulheres mais amplo e com outros atores na sociedade civil e política, o Estado e instituições internacionais; (2) controvérsias geradas pelas recorrentes crises de 'inclusão' e de 'expansão' do movimento; e (3) debates centrados nas diferenças, desigualdades e desequilíbrios de poder entre mulheres em geral e entre as feministas em particular.

Palavras-chave: ativismo feminista, movimentos feministas latino-americanos, feminismos transnacionais.

Copyright $\odot 2003$ by Revista Estudos Feministas 
Em novembro de 1999, aproximadamente 1.300 mulheres provenientes de praticamente todos os países da América Latina e do Caribe viajaram para a cidade costeira de Juan Dolio, na República Dominicana, para participar de um evento que muitas das ativistas da região passaram a considerar como uma arena decisiva para se reimaginar coletivamente o feminismo e a sua relação com vários outros grupos que lutam pela dignidade humana e pela justiça social. ' Desde que a primeira de tais reuniões aconteceu, em Bogotá, Colômbia, em 1981, os Encontros Feministas Latino-Americanos e Caribenhos vêm funcionando como espaços críticos transnacionais nos quais militantes locais remodelam e renegociam identidades, discursos e práticas distintivas dos feminismos da região.

O oitavo dessa série de Encontros bienais ou trienais, o evento de Juan Dolio anunciado como "o último Encontro do milênio" - teve como objetivo fazer uma avaliação das últimas três décadas de feminismo na região. As organizadoras dominicanas apresentaram os objetivos do Encontro, subdivididos em três partes: 1) produzir um balanço dos últimos 30 anos das ações feministas na América Latina e no Caribe; 2) criar espaços de diálogo que pudessem avançar a análise feminista e posicionamentos políticos vis-àvis "novas" e "antigas" formas de opressão; e 3) identificar os mínimos denominadores comuns que promovessem a criação de elos e alianças dentro do movimento de mulheres latino-americanas e caribenhas. ${ }^{2}$

Como participantes deste Encontro, assim como de Encontros anteriores, e como analistas dos feminismos latino-americanos, e tendo ligações várias e extensas com militantes e acadêmicas por toda a região, nós percebemos que a agenda do Encontro de Juan Dolio também nos oferecia uma oportunidade única para refletirmos coletivamente sobre as dinâmicas passadas e presentes e sobre os prospectos futuros dos feminismos no Sul das Américas. ${ }^{3}$ Nosso interesse em comum de trazer as experiências latino-americanas para o centro dos recentes debates a respeito da 'internacionalização' ou 'globalização' dos feminismos serviu como mais uma inspiração para este ensaio em conjunto. Enquanto muito da literatura recente sobre a organização transnacional do feminismo tem enfocado como as arenas públicas 'oficiais' internacionais, como as conferências da ONU, promoveram vínculos entre as feministas para além das fronteiras dos Estados-nação, as acadêmicas, em grande parte, têm ignorado a história rica dos processos 'extra-oficiais', como os Encontros, através dos quais feministas se juntam dentro de regiões particulares

\footnotetext{
${ }^{1}$ As autoras gostariam de agradecer a todas as feministas latino-americanas e caribenhas que compartilharam seus insights, palavras e tempo conosco. As três autoras que trabalharam como coordenadoras e principais editoras dos vários rascunhos desse ensaio conjunto são as primeiras da lista; as outras co-autoras aparecem em ordem alfabética.

${ }^{2}$ Esse sumário é de um panfleto de julho de 1999, elaborado pelo Comitê Organizador do VIII Encontro, intitulado "Convocación General".

${ }^{3}$ Uma de nós participou de todos os oito Encontros Latino-Americanos e Caribenhos; outra de cinco, uma participou de três, duas de nós de dois, e três de nós participamos de um desses encontros regionais. Entre nós, já conduzimos pesquisa e participamos de inúmeras atividades locais e nacionais dos movimentos feministas e de mulheres na Argentina, no Brasil, no Chile, no Peru, na Colômbia, na Nicarágua, em Cuba, na Guatemala, em El Salvador, na Venezuela e no México. Além disso, muitas de nós participamos e conduzimos pesquisa sobre o envolvimento das mulheres latino-americanas no processo de várias conferências da ONU, incluindo Nairóbi, Rio, Viena, Cairo e Pequim. Também trazemos uma ampla variedade de trajetórias feministas, políticas e intelectuais e de perspectivas culturais, étnico-raciais, sexuais, geográficas e de geração para a escrita deste ensaio. Coletivamente, nossas atividades de pesquisa e de ensino englobam uma série de disciplinas: história, literatura, estudos culturais, antropologia, sociologia e ciências políticas. A designação "Sul das Américas" marca a transição das demarcações geopolíticas da Guerra Fria de primeiro/terceiro mundos para uma ênfase no realinhamento do capital e do poder ao longo de um vetor Norte/Sul no atual contexto neoliberal da globalização.
} 
para construir solidariedade, pensar formas inovadoras de prática política e elaborar discursos que desafiam a opressão sexual e baseada em gênero. ${ }^{4}$ Além disso, o enfoque predominante nas conferências ligadas à ONU geralmente deixa passar como esses elos transnacionais alternativos afetam a dinâmica dos movimentos em níveis locais e nacionais. Ao analisar os Encontros latino-americanos e caribenhos, desejamos chamar a atenção para processos feministas intra-regionais, centrados nos movimentos, e para os seus efeitos locais, destacando, assim, a interação dinâmica e mutuamente constitutiva de identidades, discursos e práticas feministas nacionais e transnacionais.

Em um artigo de 1992, que foi o produto de uma conversa interdisciplinar semelhante à nossa, Nancy Sternbach, Marysa Navarro-Araguren, Patricia Chuchryk e Sonia E. Alvarez sugeriram que os Encontros funcionam como "marcadores históricos, destacando os mais importantes debates estratégicos, organizacionais e teóricos que caracterizaram a trajetória política dos feminismos latino-americanos". ${ }^{5}$ Enquanto este ensaio também vai explorar como os Encontros 'marcaram' os debates da região, também vamos argumentar que eles são, em si mesmos, espaços entre-fronteiras ou transfronteiriços, que não apenas refletem, mas que também reconfiguram os discursos e as práticas dos movimentos locais, nacionais e regionais.

Enquanto os feminismos na região surgiram de uma grande diversidade de lutas políticas e localidades sociais, os Encontros permitiram que as militantes pudessem compartilhar suas diferentes perspectivas e construir significados políticos e culturais alternativos. Apesar de muitas vezes serem politicamente marginalizadas em seus países, as participantes dessas conversas regionais periódicas puderam se engajar com outras cujos feminismos emergem de condições sociopolíticas e heranças coloniais e neocoloniais análogas. Em uma região em que a Esquerda inicialmente via o feminismo como uma 'importação burguesa e imperialista' que dividia a luta de classes, e em que a Direita e a Igreja o denunciaram como uma afronta às normas culturais nacionais e aos valores da família cristã, nós argumentamos que os Encontros provaram ser arenas transnacionais fundamentais onde identidades e estratégias especificamente latino-americanas têm sido constituídas e contestadas.

Mais do que apenas um fértil espaço de confluência, esses Encontros regionais têm ajudado a 'imaginar' comunidades feministas latino-americanas. Eles têm sido cruciais ao desafiar normas culturais nacionalistas masculinistas e ao criar uma gramática política feminista comum (mesmo que sempre contestada). Como a teórica feminista peruana Virginia Vargas argumenta, "Essa ação feminista transnacional foi orientada fundamentalmente para a recriação de práticas coletivas, fazendo uso de novas categorias analíticas, novas visibilidades, e até mesmo de novas linguagens inventadas pelos feminismos em nível nacional, nomeando aquilo que até então não tinha nome: sexualidade, violência doméstica, assédio sexual, estupro conjugal, a feminilização da pobreza, etc.". ${ }^{\circ}$ Os Encontros também promoveram novas modalidades de ativismo transfronteiras. De fato, um produto-chave desses diálogos tem sido a formação de numerosas redes intra-regionais que tratam de questões e identidades específicas, assim como coalizões de advocacy (ou promoção e defesa de direitos) relacionadas a uma

\footnotetext{
${ }^{4}$ Para uma amostragem dessa literatura sobre a organização transnacional do feminismo, ver: Arvonne FRASER, 1987; Deborah STIENSTRA, 1994; Elisabeth FRIEDMAN, 1995; Carolyn STEPHENSON, 1995; Bella ABZUG, 1996; Martha CHEN, 1996; Nuket KARDAM, 1997; Ann Marie CLARK, Elisabeth FRIEDMAN e Kathryn HOCHSTETLER, 1998; Margaret KECK e Kathryn SIKKINK, 1998; Mary MEYER e Elisabeth PRÜGL, 1999; Amrita BASU, 2000.

${ }^{5}$ STERNBACH, NAVARRO-ARAGUREN, CHUCHRYK e ALVAREZ, 1992, p. 395.

${ }^{\circ}$ VARGAS, 1999, p. 30.
} 
série de questões como a saúde da mulher e direitos sexuais e reprodutivos, violência contra a mulher, e representação política das mulheres. ${ }^{7}$

Essas conversas regionais periódicas também ajudam a reorientar as práticas do movimento, os discursos culturais e até as políticas estatais, à medida que as participantes aprendem com a experiência de suas semelhantes de outros países da região e, geralmente, voltam para casa inspiradas pelas novas estratégias organizacionais e pelas novas formas de enquadrar e encaminhar suas questões e reivindicações. Os discursos e estratégias em debate nesses espaços transnacionais do movimento, por sua vez, são traduzidos e adaptados de acordo com contextos locais e nacionais específicos. Sugerimos ainda que os movimentos locais têm se beneficiado com a alternância dos países que sediam os Encontros, já que cada Encontro enfatiza questões ou problemas específicos do país-sede, permitindo que esses problemas sejam discutidos e, às vezes, resolvidos em um ambiente supranacional(ista). Defendemos que os Encontros, dessa forma, representam um espaço mediador de vital importância entre arenas nacionais, regionais e globais do movimento.

Considerando os Encontros como espaços produtivos de transformação - facilitando uma interação dinâmica entre lutas locais/nacionais e processos regionais - analisamos como eles se mostraram espaços críticos de negociação. Dadas as diferenças de classe, as divisões cidade/campo, a diversidade das formações raciais e étnicas, as diferenças de idade e de gerações, assim como as diferenças de identidades e de orientação sexual, a heterogeneidade dos feminismos latino-americanos e caribenhos tem desafiado uma compreensão uniforme de algumas questões-chave do movimento feminista como saúde reprodutiva, educação, violência contra mulheres, direitos trabalhistas, sexualidade e globalização (neoliberal). As participantes são mulheres engajadas na militância feminista em uma ampla variedade de espaços públicos (potencialmente antagônicos) - desde grupos de feministas lésbicas a sindicatos trabalhistas, movimentos dos sem-terra, organizações não-governamentais (ONGs), departamentos de estudos da mulher em universidades, organizações revolucionárias, partidos políticos e instituições governamentais. Mesmo que ancorados na solidariedade política entre mulheres, então, os Encontros e os 'desencontros' dentro deles têm propiciado debates produtivos e reconfigurado alianças e coalizões entre as feministas da região.

A seguir, vamos explorar os pontos-chave do debate que produziu coalizão e controvérsia, consenso e conflito, encontros e desencontros, entre as diversas correntes dos feminismos latino-americanos nos sete primeiros desses eventos regionais - Bogotá, Colômbia (1981); Lima, Peru (1983); Bertioga, Brasil (1985); Taxco, México (1987); San Bernardo, Argentina (1990); Costa del Sol, El Salvador (1993); e Cartagena, Chile (1996). A estória que contamos examina debates essenciais do movimento como foram representados em cada um dos Encontros, enfocando particularmente aqueles dos anos 1990 . Argumentamos que coalizões, conflitos e controvérsias que emergiram em contextos nacionais ou sub-regionais específicos têm sido re-encenados e, às vezes, reescritos nessas arenas transnacionais. Os debates e as tensões que se desenrolam nesses Encontros, por sua vez, têm sido freqüentemente revividos nas esferas locais e nacionais do movimento destacando, assim, a constituição mútua do nacional e do transnacional. Exploramos três temas em torno dos quais esses debates giraram: 1) mudanças nas concepções de 'autonomia' do movimento e na relação dos feminismos com o movimento de mulheres

\footnotetext{
${ }^{7}$ Para análises das práticas feministas de advocacy, ver Sonia ALVAREZ, Marlene LIBARDONI e Vera SOARES,
} 2000. 
mais amplo e com outros atores na sociedade civil e política, o Estado, e instituições internacionais; 2) controvérsias geradas pelas recorrentes crises de 'inclusão' e de 'expansão' do movimento; e 3) debates centrados nas diferenças, desigualdades e desequilíbrios de poder entre mulheres em geral e entre as feministas em particular.

A última parte do nosso ensaio volta-se para uma análise detalhada do Oitavo Encontro, onde atritos novos e antigos foram reproduzidos e debates de longas datas entre feministas foram revistos - proporcionando uma perspectiva única em relação a desafios fundamentais que o movimento enfrenta hoje. ${ }^{8}$ À medida que novas gerações e atores de origens cada vez mais diversas participam dos Encontros, a definição do que seja o feminismo e as modalidades através das quais as lutas feministas devem ser travadas vêm sendo profundamente questionadas. No contexto das mudanças nas coordenadas políticas e econômicas dos anos 1990 - marcadas pelo capitalismo neoliberal e por uma democratização parcial e desigual - os espaços, alvos e objetivos apropriados da política feminista e, de fato, o próprio significado do feminismo em si tornaram-se objetos de conflito intenso entre as militantes. O Oitavo Encontro cristalizou essas novas tendências e trouxe à tona tensões não resolvidas que também haviam emergido nos dois Encontros anteriores. Para melhor entender o que transpirou em Juan Dolio, contudo, precisamos primeiro situar esse último Encontro à luz da história de duas décadas de Encontros latino-americanos e caribenhos.

\section{A primeira década de Encontros: negociando políticas, produzindo identidades feministas}

Os debates que aconteceram durante a primeira década dos Encontros, realizados entre 1981 e 1990, refletiram as mudanças de significado do feminismo na região. Como Sternbach et al. ${ }^{9}$ argumentam, as discussões nos primeiros cinco Encontros giraram em torno de dois pontos principais: primeiro, a relação entre os movimentos feministas e a Esquerda masculina revolucionária, e mais tarde, à medida que o movimento crescia, a relação entre os movimentos feministas e o mais amplo movimento de mulheres, que surgiu no contexto da crise econômica e de violação dos direitos humanos generalizados por toda América Latina e Caribe. ${ }^{10}$

Central para a compreensão da primeira década de Encontros é o ideal da autonomia feminista - amplamente aceito, mas veementemente contestado - considerado por muitas como a pedra fundamental da identidade feminista na América Latina e no Caribe. Se os movimentos feministas da região caracterizam-se por um desejo de construir alianças com diversos setores da sociedade (especialmente outras mulheres), com o objetivo de erradicar a opressão baseada no gênero, ao mesmo tempo o ideal de autonomia é invocado para evitar a cooptação por atores como partidos políticos, o Estado, as agências de cooperação e até outros movimentos sociais. Assim, as feministas têm se preocupado profundamente em expandir o número de participantes, o alcance e a influência do feminismo, ao mesmo tempo em que se recusam a sacrificar a autonomia ideológica, política, organizacional e financeira dos seus movimentos. Enquanto a

\footnotetext{
${ }^{8}$ Para outros apanhados recentes sobre os movimentos feministas latino-americanos, ver: ALVAREZ, 1998; Jane JAQUETTE e Sharon WOLCHIK, 1998; Marysa NAVARRO e Susan BOURQUE, 1998; Nikki CRASKE, 2000; DEVELOPMENT..., 2000; Maxine MOLYNEUX, 2000; Virginia VARGAS, 2000; Maruja BARRIG, 2001 a; Jean FRANCO, 2001.

${ }^{9}$ STERNBACH et al., 1992.

${ }^{10}$ Sobre o movimento de mulheres, ver Elisabeth JELIN, 1990; Amy LIND, 1992 e 1995; e Lynn STEPHEN, 1997 e 1998.
} 
autonomia, definida em termos gerais aqui como a capacidade de agir independentemente, tem sido vista como a 'palavra mágica' dos feminismos latinoamericanos e caribenhos, também tem sido (e continua a ser) uma questão espinhosa: do que e de quem exatamente as feministas devem manter autonomia? ${ }^{11}$

Nos anos 1970 e no início dos anos 1980, a autonomia foi invocada quase que exclusivamente em relação a partidos políticos ou a organizações revolucionárias de Esquerda. Como já foi bem documentado, as feministas do início da segunda onda, na sua maioria, compartilhavam as mesmas experiências em partidos políticos de Esquerda ou em movimentos revolucionários. Questionando a suposta neutralidade com relação às questões de gênero do projeto socialista e reconhecendo que a opressão de gênero transcende a exploração capitalista, muitas feministas cada vez mais optaram por abandonar a militância partidária em favor da criação de suas próprias organizações independentes, como associações, centros de estudo e grupos de conscientização. ${ }^{12}$

Como era de se esperar, então, a primeira maior tensão filosófica e estratégica que as feministas da segunda onda se confrontaram foi entre aquelas que se proclamavam feministas e aquelas às quais se referiam como as políticas, mulheres que continuaram a trabalhar dentro de organizações partidárias de Esquerda. Presente de forma mais clara nos primeiros dois Encontros em Bogotá, Colômbia (1981), e em Lima, Peru (1983), esse conflito estabeleceu a 'autonomia' como uma prática que definia quem era (e quem não era) feminista. Para as feministas, a forma como a Esquerda descartava o feminismo como sendo uma importação burguesa de nações imperialistas tornava impossível a criação de um espaço para a política feminista dentro das estruturas partidárias. Além disso, as feministas passaram a ver as estruturas hierárquicas então típicas da Esquerda como inerentemente patriarcais e, portanto, contrárias às transformações radicais culturais e éticas implicadas nas suas lutas. Para as feministas, então, a autonomia passou a ser definida como "independência de qualquer organização que considere a batalha pela liberação das mulheres um objetivo secundário". ${ }^{13}$ As políticas, ao contrário, defendiam uma estratégia de dupla militância ou participação concomitante em organizações feministas e partidárias revolucionárias. Para as feministas nos primeiros dois Encontros, as políticas eram 'programadas' pela Esquerda e freqüentavam encontros feministas apenas para 'divulgar sua mensagem'. As políticas, por outro lado, viam os Encontros (e, até certo ponto, 'o feminismo autônomo') como um projeto pequeno burguês, argumentando que as feministas só poderiam atingir as 'massas' das mulheres através da organização partidária de Esquerda e da mobilização revolucionária.

Os debates acirrados encenados nos Encontros do início dos anos 1980 inspiraram muitas militantes na tentativa de superar posicionamentos tão polarizados e ajudaram a produzir novas formas de se entender como as feministas poderiam continuar a ser 'autônomas' e ao mesmo tempo manter vínculos com outras lutas por justiça social. Como uma participante observou em Bogotá, "A grande maioria das mulheres apoiaram a

\footnotetext{
${ }^{11}$ Nos anos 1970, "a palavra mágica incorporada foi autonomia, compreendida de maneiras diferentes por diferentes grupos. Autonomia em relação aos homens (defendida por muitos grupos), autonomia em relação aos partidos políticos (alguns grupos), e autonomia em relação ao estado (†odos os grupos)" (Maria Aparecida SHUMAHER e Elisabeth VARGAS, 1997, p. 129).

${ }^{12}$ A feminista peruana Ana María PORTUGAL (1986) observa que as mulheres de esquerda originalmente viam as feministas norte-americanas, as que "queimam sutiãs", como "gringas entediadas"; contudo, à medida que "as companheiras continuavam a usar suas armaduras feudais em casa, o mundo doméstico no qual a revolução nunca vai acontecer", mais e mais mulheres começaram a levar o feminismo a sério ( $p$. 10).

${ }^{13}$ BARRIG, 2001 a, p. 159, cita um documento de 1980 assinado por um grupo de feministas peruanas.
} 
autonomia de suas organizações e práticas, o que não significa que nós rejeitamos a participação de mulheres em partidos políticos. [...] Defendemos que eles não deveriam trazer slogans, agendas e objetivos políticos que não digam respeito aos interesses das mulheres. Isso também não quer dizer que o feminismo deva se isolar, se separar ou ignorar outros movimentos sociais". ${ }^{14} \mathrm{Na}$ verdade, depois de meados dos anos 1980, o termo 'feminismo autônomo' pareceu ter-se tornado redundante. O debate feminista/política perdeu sua força, à medida que muitas feministas revisaram sua compreensão do que poderíamos chamar de 'autonomia engajada' - negociando com, ou participando de movimentos e partidos revolucionários e de Esquerda, bem como de instituições sociais e políticas dominantes, mantendo, ao mesmo tempo, uma postura crítica e feminista. À medida que se desencadearam transições de governos autoritários para governos civis no Brasil, no Cone Sul e na Região Andina, outras ainda se afiliaram a partidos legais da oposição - mas o fizeram proclamando com orgulho suas identidades feministas e insistindo para que a oposição abraçasse a causa feminista.

Mesmo à medida que o debate sobre a participação feminista em partidos políticos perdia a força, o ideal da 'autonomia' continuou a informar o discurso e a prática feministas por toda a região, especialmente no que se refere aos Encontros. Os princípios organizadores estabelecidos para o Primeiro Encontro, em 1981, que seriam seguidos a cada Encontro subseqüente, foram elaborados visando a preservar tanto a 'autonomia' como a capacidade de 'inclusão' do evento - e, implicitamente, do próprio feminismo. Esperavase que as mulheres participassem do evento enquanto "indivíduos, e não como representantes ou delegadas de partidos, sindicatos, ou de outras organizações". ${ }^{15}$ O evento seria, assim, um verdadeiro Encontro, e não um congresso político estruturado de forma rígida, muito menos uma conferência acadêmica mais formal, refletindo o desejo de se criar novas formas, não-hierárquicas e mais participativas, de fazer política. Acreditandose que qualquer financiamento externo comprometeria politicamente o evento, os três primeiros Encontros foram totalmente autofinanciados.

Além disso, os Encontros deveriam ser amplos, antecipando o segundo grande debate dos anos 1980, em torno das práticas de inclusão e de exclusão do feminismo. Como o ideal da autonomia, a proposta de inclusão dos Encontros sempre foi uma questão polêmica, na medida em que parecia presumir como já resolvidas as seguintes questões: quem poderia ser considerada 'feminista' o suficiente para participar dos Encontros, e, mais amplamente, a quem o feminismo deveria convocar em primeiro lugar? Enquanto as participantes do Segundo Encontro (Lima, 1983), na sua grande maioria, rejeitaram a criação de um feministômetro para indicar quem era mais ou menos feminista, Encontros posteriores viriam a questionar o compromisso do feminismo com a inclusão, especialmente em relação a classe, raça, etnia e sexualidade.

O dilema da inclusão tornou-se particularmente relevante em parte porque os movimentos feministas da segunda onda na América Latina e no Caribe sempre viram as mulheres pobres e da classe trabalhadora como um alvo ou clientela-chave. Os anos 1980, marcados por uma opressão estatal brutal e um empobrecimento crescente, apresentaram novas oportunidades e desafios para a criação de um movimento feminista de bases mais amplas, à medida que milhares de mulheres começaram a se mobilizar politicamente -mesmo que não necessariamente como feministas - como resposta a crises

\footnotetext{
${ }^{14}$ Frida MANRIQUE, 1981.

${ }^{15}$ Amalia FISHER, 1995, p. 29.
} 
econômicas, à repressão política e às violações dos direitos humanos. Em contraste à face branca/mestiça e de classe média do feminismo nos seus primeiros tempos, o movimento de mulheres dos anos 1980 floresceu com uma composição predominante de mulheres pobres, trabalhadoras, e/ou negras e indígenas. ${ }^{16}$ As dificuldades em construir pontes entre diferentes expressões do movimento de mulheres e feministas - marcadas pelas imensas desigualdades estruturais e diferenças políticas - vieram claramente à tona no Terceiro Encontro em Bertioga, Brasil (1985), quando um grupo de mulheres de uma favela do Rio de Janeiro chegou em um ônibus, pedindo para poder participar, apesar de não ter condições de pagar a taxa de inscrição. Mesmo com um número significativo de mulheres negras e pobres já participando, a crise persistente do feminismo com relação à inclusão e exclusão literalmente se estacionou na porta desse Encontro. As organizadoras brasileiras haviam de fato assegurado várias bolsas para possibilitar a participação de mulheres pobres, e muitas participantes suspeitaram que o incidente do ônibus foi orquestrado por partidos políticos em uma tentativa de desacreditar o feminismo. De qualquer forma, muitas das participantes, especialmente militantes do então emergente movimento de mulheres negras, insistiram que as questões de raça e classe não ocupavam um lugar central na agenda do Encontro e que as mulheres negras e pobres não haviam tido uma participação significativa na elaboração dessa agenda. Obviamente, as desigualdades de raça e classe dificilmente são resolvidas com a simples 'inclusão' de mulheres de classe trabalhadora e não-brancas nos 'ranks' do feminismo. Como a nossa discussão subseqüente vai mostrar, o movimento continua a lutar com as maneiras com que os privilégios de classe, raça e de orientação sexual hetero estruturaram as relações de poder entre as mulheres na sociedade e dentro do próprio feminismo.

Se o Encontro de Bertioga trouxe o dilema da inclusão a primeiro plano, os novos desafios postos pela expansão do movimento entre mulheres pobres, trabalhadoras e nãobrancas tornaram-se dramaticamente evidentes no Quarto Encontro em Taxco, México (1987), em que participaram mais de 1.500 mulheres. A participação sem precedentes de centenas de mulheres do movimiento de mujeres, especialmente da América Central, parecia sinalizar que o movimento feminista havia alcançado seu objetivo de promover um Encontro com bases verdadeiramente amplas. Essa abertura pode ser atribuída aos esforços concentrados das militantes em trazer as perspectivas feministas para as organizações de mulheres das classes populares. A presença maciça de mulheres politicamente ativas novas no feminismo, contudo, foi vista como problemática por algumas. Muitas feministas históricas (militantes de longa data) acreditavam que a presença maciça do movimiento de mujeres impedia a elaboração de 'A' agenda feminista e era contraproducente para o avanço da produção do conhecimento feminista. Frustradas pelo que percebiam como o nível elementar do discurso das participantes das classes populares, muitas demonstraram impaciência ao terem que ficar ensaiando o 'básico', quando desejavam seguir adiante no debate feminista.

Em Taxco, um bom número de feministas antigas defenderam que os Encontros não deveriam ser uma "escola feminista" para "as massas", mas sim um espaço para a recuperação de idéias e práticas feministas. Outras viram essa atitude como um ressurgimento do "feministômetro" e rejeitaram a pressuposição de que as mulheres centroamericanas, indígenas ou pobres não fossem 'feministas' o suficiente para participarem. A

\footnotetext{
${ }^{16}$ Sobre mulheres nos movimentos pelos direitos humanos, ver NAVARRO, 1989; Diana TAYLOR, 1997; e Rita ARDITTI, 1999. Sobre a participação de mulheres em lutas populares pela sobrevivência, ver Teresa CALDEIRA, 1990; JELIN, 1990; Vivienne BENNETT, 1992; LIND, 1992; Alejandra MASSOLO, 1992; e STEPHEN, 1997.
} 
proposta da realização de dois Encontros no futuro, um para as feministas e outro para o movimiento de mujeres, se deparou com um coro de centenas de mulheres cantando "Todas somos feministas", o que permitiu uma maior percepção de que o feminismo não 'pertence' a ninguém.

A idéia de que qualquer mulher que se considere uma feminista seja uma feminista - no que terminou por se tornar uma solução contingente para a persistente tensão dentro do feminismo sobre inclusão e expansão - ecoou no Encontro seguinte, realizado em San Bernardo, Argentina, em 1990. ${ }^{17}$ Com 3.200 participantes, foi o maior Encontro até agora. De fato, o Encontro de San Bernardo parecia sugerir que os feminismos latino-americanos e caribenhos haviam atingindo proporções massivas. A presença de mulheres de uma vasta arena do quehacer feminista, incluindo grupos independentes, sindicatos, ONGs, universidades, ministérios de mulheres recém-criados, e até parlamentares eleitas, sinalizaram que até 1990 a prática feminista tinha adquirido significativamente novas dimensões. A presença simultânea de mulheres de grupos 'autônomos', de centros de estudo e de arenas 'institucionalizadas' como partidos políticos e o Estado sugeria que os 'velhos' debates sobre autonomia haviam sido aparentemente superados.

Um outro desenvolvimento em San Bernardo foi a presença marcante de redes formais intra-regionais do movimento. Algumas delas, como a Rede Latino-Americana e Caribenha de Mulheres Negras, fundada em San Bernardo, e a rede feminista lésbica, formada em 1987 em um encontro regional anterior a Taxco, procuraram construir a solidariedade e elaborar estratégias para tratar o racismo, o heterossexismo e outras questões geralmente marginalizadas nas agendas feministas nacionais e regionais, e combater a invisibilidade das 'Outras' mulheres no movimento. Essas redes se juntaram no Quinto Encontro com novas redes e coalisões regionais - como Rede Latino-Americana de Saúde e Direitos Reprodutivos - centradas em advocacy, na defesa e promoção de políticas nacionais e internacionais. Enquanto durante os anos 1980 essa última forma de trabalho em redes era relativamente rara, redes centradas em políticas cresceram significativamente em visibilidade e influência nos anos 1990 - em grande parte devido ao crescente envolvimento dos feminismos latino-americanos e caribenhos com o processo das conferências da ONU.

O número significativo de feministas agora engajadas na advocacy de políticas de gênero e a crescente visibilidade em San Bernardo de feministas ativas em partidos legais em vez de partidos clandestinos de Centro e de Esquerda, envolvidas em política eleitoral ou empregadas em agências estatais, refletiram o novo contexto político em que o feminismo estava inserido no início dos anos 1990. A seguir, iremos explorar a forma como as feministas lidaram com as 'transições gêmeas' na América Latina - rumo à democracia política e ao neoliberalismo econômico.

\section{A autonomia revisitada: redimensionando as estratégias e Identidades feministas nos Encontros dos anos 1990}

O crescente envolvimento das feministas em esforços de advocacy cada vez mais profissionais e especializados, tanto nacional como internacionalmente, reacendeu e

\footnotetext{
${ }^{17} \mathrm{Na}$ última sessão plenária, foi declarado que "todas as mulheres que lutam para melhorar a situação real do gênero feminino serão consideradas feministas". As feministas históricas foram criticadas como "aquelas fundadoras do feminismo que se apropriaram dele para si próprias, e que empregam categorias que não apenas são obsoletas como também discriminatórias contra as mulheres que estão chegando no movimento" (Francesca GARGALLO, 1991, p. 15-16).
} 
reposicionou os antigos debates entre feministas em toda a região. Se os conflitos históricos do movimento acerca da autonomia, da inclusão e expansão pareceram ter sido amainados no Encontro de San Bernardo, ressurgiram com força renovada nos três Encontros seguintes dos anos 1990 - Costa del Sol, El Salvador (1993); Cartagena, Chile (1996); e Juan Dolio, República Dominicana (1999).

A questão sempre contenciosa da autonomia agora viria girar em torno de um novo eixo: o engajamento cada vez maior de algumas feministas em instituições políticas nacionais e internacionais - visto por algumas como um "passo necessário" para o avanço da agenda transformadora feminista, mas também visto por outras como um desvio perigoso em direção ao "patriarcado global neoliberal" ou, até mesmo, em conluio com esse patriarcado. As tensões em torno de quem seria incluída na comunidade feminista 'verdadeira' (mesmo que sempre 'imaginada') também foram novamente colocadas nos Encontros regionais de Costa del Sol e Cartagena sob essa mesma perspectiva: deveriam as militantes agora predominantemente envolvidas em arenas de políticas 'masculinistas' ser vistas simplesmente como a vertente da advocacy do movimento, ou estariam elas se 'vendendo', ou, pior ainda, seriam elas 'traidoras' da causa feminista?

Para compreendermos a rearticulação das tensões acerca da autonomia, da inclusão e da expansão entre as feministas, devemos considerar os contextos nacionais e internacionais em que tomaram forma duas 'lógicas' que caracterizaram os movimentos feministas nos anos 1990. Por um lado, uma lógica de 'advocacy de políticas' impulsionou os esforços de números crescentes de militantes buscando promover políticas de gênero feministas em instituições governamentais e não-governamentais. Por outro lado, uma lógica de 'identidade-solidariedade' permaneceu evidente no desenvolvimento de identidades, comunidades, políticas e idéias, centradas no movimento, e que rejeitavam ou, pelo menos, não estavam diretamente direccionadas às instituições formais da política. ${ }^{18}$

Muito antes de Cartagena e já pressagiada em San Bernardo, a lógica da advocacy de políticas havia começado a influenciar muito a militância feminista local e regional. Os fatores domésticos por trás dessa mudança estavam enraizados na dupla transição para a democracia política e a reforma econômica neoliberal. No campo político, governos e partidos responderam ao papel importante que os movimentos de mulheres desempenharam na derrubada de regimes autoritários por toda a região, assim como a uma preocupação em atrair mulheres eleitoras, abraçando, ao menos retoricamente, várias questões feministas como cotas eleitorais e legislação sobre a violência doméstica. ${ }^{19}$ Esse esforço proporcionou oportunidades simbólicas e materiais para a articulação de políticas feministas a partir de dentro de instituições formais, especialmente com a fundação de secretarias ou ministérios nacionais de e para as mulheres em quase todos os países da região. As feministas estavam não apenas cada vez mais entrando em peso no aparato governamental e em partidos, como também começaram a desenvolver lutas por políticas de gênero baseadas na sociedade civil, fundando ONGs. Isso, por sua vez, levou a uma crescente especialização e profissionalização entre as militantes e organizações do movimento. ${ }^{20}$

Mais adiante, essas transformações foram estimuladas pelo desenvolvimento econômico, à medida que políticas reformistas, inclusive o enxugamento do Estado, resultaram na transferência de programas de bem-estar social, antes bancados pelo Estado,

\footnotetext{
${ }^{18}$ ALVAREZ, 2000.

${ }^{19}$ Sobre os ganhos recentes das políticas de gênero dos anos 1990, ver Sara NELSON, 1996; Mala HTUN, 1998; JAQUETTE e WOLCHIK, 1998; Maria Cecília DOS SANTOS, 2000; e Giulia TAMAYO, 2000.

${ }^{20}$ Nathalie LEBON, 1993 e 1998; ALVAREZ, 1999; e Donna MURDOCK, a ser publicado.
} 
para as ONGs, inclusive muitas daquelas voltadas para as mulheres. ONGs feministas interessadas em tais atividades se viram obrigadas a formalizar suas práticas organizacionais e a moderar seus discursos para poderem interagir com agências governamentais e instituições internacionais. ${ }^{21}$

Fatores internacionais, mais notadamente as conferências da ONU nos anos 1990, reforçaram o crescente direcionamento de muitos grupos nacionais para a elaboração de políticas públicas. ${ }^{22} \mathrm{~A}$ participação efetiva no sistema da ONU exigia habilidades cada vez mais especializadas, mais recursos materiais, e alianças com organizações governamentais e instituições internacionais. Além disso, essa participação foi em grande parte financiada por agências de cooperação internacional multilaterais, bilaterais e nãogovernamentais. Já predispostas a financiar organizações com uma estrutura e orientação mais profissionais (e às vezes governamentais), as agências privilegiaram aqueles grupos mais dispostos a dedicar suas energias à arena internacional nos anos 1990. ${ }^{23}$

A interação dessas influências domésticas e internacionais inspiraram um grande número de militantes a criar vínculos intra e inter-regionais para participar dos processos na ONU. Elas esperavam que a pressão internacional pudesse ser rebatida (boomeranged) para os governos nacionais e locais a fim de assegurar a implementação da legislação e dos programas sobre os direitos das mulheres iniciados durante os processos de democratização. ${ }^{24}$ Como foi explicado por uma das mais proeminentes líderes do processo de preparação da Quarta Conferência Mundial de Mulheres, "uma das mudanças mais significativas [nos anos 1990] foi a mudança de uma postura anti-estadista para uma postura crítica de negociação com o Estado e instituições internacionais formais". ${ }^{25}$

Durante os anos 1990, a lógica da advocacy de políticas funcionou tanto como complemento quanto como competidora da lógica da identidade/solidariedade das militantes mais de base e menos profissionalizadas. Por um lado, as duas lógicas se complementaram, à medida que as coordenações de ONGs para as conferências da ONU, como a de Beijing, basearam-se em contatos e discursos construídos através de redes de identidade e solidariedade preexistentes, e, na sua maioria, informais, enquanto que a luta das feministas locais se beneficiou da legitimação de algumas questões feministas históricas, agora oficialmente abraçadas pela ONU e nominalmente apoiadas por muitos dos governos da região.

Contudo, surgiu conflito quando a preferência por líderes e por discursos mais amenos à política tradicional foi vista como uma ameaça à solidariedade feminista. O acesso desproporcional aos recursos, à atenção e aos financiamentos governamentais das militantes que seguiram a lógica de advocacy de políticas tornou-se uma fonte profunda de atritos entre feministas em toda a região. Particularmente, a óbvia moderação das críticas e propostas mais radicais dos feminismos provocou um novo segmento do movimento

\footnotetext{
${ }^{21}$ CRASKE, 1998; e Verónica SCHILD, 1998.

${ }^{22}$ Essas conferências incluem a Conferência das Nações Unidas para o Meio Ambiente e Desenvolvimento, realizada no Rio de Janeiro, em 1992; a Conferência para os Direitos Humanos, realizada em Viena, em 1993; a Conferência da ONU sobre População e Desenvolvimento, realizada no Cairo, em 1994; a Quarta Conferência Mundial de Mulheres, realizada em Pequim, em 1995; o Encontro Mundial para o Desenvolvimento Social, em Copenhague, em 1995; e a Segunda Conferência da ONU sobre Assentamentos Humanos (Habitat II), realizada em Istambul, em 1996.

${ }^{23}$ ALVAREZ, 1998.

${ }^{24}$ KECK e SIKKINK, 1998.

${ }^{25}$ VARGAS, 1998a, p. 15.
} 
a condenar visceralmente tudo aquilo que fosse 'institucionalmente relacionado', reacendendo o ideal da autonomia, agora adaptando-o às novas circunstâncias dos anos 1990.

\section{Costa del Sol, El Salvador, 1993}

Poucas esperavam que a renovada tensão acerca da autonomia iria tomar conta da agenda do Sexto Encontro, realizado em Costa del Sol, El Salvador, no final de 1993. Afinal, o próprio fato de que a América Central - onde muitas feministas haviam continuado a se engajar em uma 'militância dupla' em partidos revolucionários e em movimentos populares radicais durante os anos 1980 e 1990 - havia sido escolhida como o local do Sexto Encontro feminista regional parecia sugerir que muitas feministas haviam deixado de lado suas convicções anteriores de que o ativismo partidário e a prática feminista eram ontologicamente incompatíveis. Também sinalizou um reconhecimento de que o feminismo da América Central - com sua história particular na Costa Rica; seu nascimento no calor da revolução e da guerra civil na Nicarágua, El Salvador e Guatemala; e suas ligações com lutas contra a ocupação militar e pela terra em Honduras - tinha algo importante a oferecer às feministas de outras partes da América Latina e do Caribe.

O caminho para comparecer aos Encontros anteriores havia sido longo e difícil, especialmente para as mulheres guatemaltecas e salvadorenhas vindas de guerras civis violentas. A decisão de realizar esse Encontro em um El Salvador destruído pela guerra havia sido tomada um ano antes em um Encontro sub-regional de militantes centroamericanas. Realizado em Montelimar, Nicarágua, esse Encontro teve o objetivo de impulsionar a força e a visibilidade dos movimentos localmente, e promover autonomia, liderança e democracia entre os feminismos centro-americanos. As intervenções de militantes revolucionárias nicaragüenses, implorando às suas companheiras na Guatemala e em El Salvador para não colocarem de lado suas demandas feministas - quando os movimentos em que participavam pregavam a unidade -, provaram ser cruciais a esse respeito, especialmente para as mulheres guatemaltecas, que, mais tarde, conseguiram incorporar as demandas das mulheres aos Tratados de Paz de 1994.

Ao mesmo tempo, surgiram tensões sobre as questões de classe e sexualidade em Montelimar quando mulheres pobres e camponesas expressaram seu mal-estar com o luxo das acomodações em um contexto onde suas crianças e comunidades eram tão necessitadas, muito embora a intenção das organizadoras nicaragüenses houvesse sido a de proporcionar às participantes um ambiente agradável para dialogar e debater. A presença visível de lésbicas também desconcertou algumas participantes, enquanto que outras, inclusive muitas das revolucionárias, aproveitaram a oportunidade para aprender sobre algo que era apenas sussurrado durante as guerras: a sexualidade.

No processo de organização do Sexto Encontro, surgiram diferenças nítidas entre as organizadoras - um grupo de mulheres politicamente diverso, que incluía exiladas e refugiadas no México - sobre as questões em torno de quem os Encontros deveriam incluir e/ou excluir e, mais importante ainda nesse caso, sobre os estilos de liderança, de debates e de tomadas de decisão trazidas dos movimentos revolucionários. Algumas das organizadoras sentiram que outras haviam simplesmente transferido seu dogmatismo e intolerância para o feminismo. Ao tempo em que reconheciam a eficiência e capacidade logística de algumas dessas líderes, muitas feministas pediam democracia, tolerância pelas diferenças e um ambiente mais encorajador para desenvolver o seu ativismo.

Isso passou a ser cada vez mais imperativo, já que as organizadoras do Sexto Encontro tiveram que confrontar uma oposição séria de políiticos de Direita em El Salvador, que 
acusaram todas as feministas de serem lésbicas, comunistas e membros da Frente Farabundo Martí de Liberación Nacional (FMLN), chegando até a ameaças de morte. Além disso, oficiais salvadorenhos proibiram mulheres cubanas de entrarem no país, e, quando participantes de outros países começaram a chegar, em torno de cem delas foram detidas no aeroporto. De fato, o Encontro eventualmente aconteceu sob a proteção das forças de paz da ONU, que na época supervisionava o processo de paz em El Salvador. Sem o conhecimento de muitas participantes, mulheres que haviam adquirido experiência em segurança durante as guerras também protegeram o Encontro dia e noite.

Apesar desse cenário de conflito políico local, o maior ponto de disputa em Costa del Sol terminou sendo se o movimento feminista latino-americano deveria participar do processo regional preparatório para a Conferência de Beijing, que seria realizada em 1995, e, se fosse o caso, em que capacidade. Pouco antes do Encontro, foi revelado que uma mulher de negócios conservadora chilena, sem ligação com o movimento feminista, havia sido designada coordenadora do fórum das ONGs para a América Latina. ${ }^{26} \mathrm{Um}$ grupo de feministas - na sua maioria do Chile - resolveu substituir a representante escolhida oficialmente por uma candidata do 'movimento'. Depois de conseguir o apoio de vários grupos feministas de toda a América Latina, elas persuadiram a secretaria da conferência a substituir a indicada oficial por Virginia Vargas, uma das fundadoras da conhecida ONG peruana Centro de la Mujer Peruana Flora Tristán. Em Costa del Sol, o grupo anunciou que a secretaria da conferência havia aceito a sua candidata alternativa, explicou como a substituição havia sido feita e também revelou que agora passaria a existir um processo de organização de ONGs feministas rumo a Beijing, que seria custeado pela Agência NorteAmericana para o Desenvolvimento Internacional (USAID).

A notícia caiu como uma bomba. As participantes, na sua maioria, não tinham experiência prévia em conferências da ONU e ainda não sabiam da conferência de Beijing. Além disso, a grande maioria das feministas latino-americanas tinha pouco contato com as novas redes internacionais envolvidas nas cúpulas mundiais. Muito embora a Década das Mulheres, criada pela ONU, tenha começado no México em 1975, as conferências da ONU tinham tido um impacto limitado nos esforços de mobilização entre as feministas latinoamericanas, com as exceções parciais do México e do Brasil. Mais preocupadas durante os anos 1980 com os acontecimentos nacionais, muito poucas das mulheres no Encontro de Costa del Sol haviam participado do 'encerramento da Década', que foi a Conferência de Mulheres da ONU em Nairóbi, em 1985, também porque coincidiu com o Terceiro Encontro em Bertioga. ${ }^{27}$ Como observamos acima, a situação começou a mudar um pouco no início dos anos 1990, à medida que aumentaram os preparativos para várias conferências da ONU. Na época do Sexto Encontro, contudo, muitas ativistas latinoamericanas não sabiam do que se tratava em um fórum de ONGs.

O fato de a agência financiadora ser a USAID também foi um problema para muitas. Além da desconfiança generalizada alimentada pela longa história de intervenção dos EUA no continente, a lembrança da ligação da USAID com a CIA e suas ações nas Américas Central e do Sul, especialmente durante a era Reagan, fez com que a aceitação de financiamento pela agência se tornasse, no mínimo, muito problemática. ${ }^{28}$ Muitas das participantes dos Encontros apoiaram a rejeição da chilena, e até concordaram com a

\footnotetext{
${ }^{26}$ Conferências governamentais oficiais da ONU geralmente são acompanhadas por um encontro ou fórum paralelo das organizações não-governamentais.

27 NAVARRO, 1998.

${ }^{28}$ Fatima MELLO, 1994.
} 
indicação de Virginia Vargas como um fato consumado. Mas muitas, mesmo assim, protestaram contra o processo, aparentemente antidemocrático, da escolha de Vargas, e questionaram por que outras 'candidatas do movimento' não foram consideradas. Os debates que se seguiram em Costa del Sol se acirraram e foram permeados por informações equivocadas e rumores de todos os tipos, inclusive sobre os altos custos do Encontro informações reveladas no ano seguinte sugeriram que as organizadoras haviam recebido cerca de meio milhão de dólares de fundações.

Em Costa del Sol, aquelas feministas que já estavam envolvidas em ONGs e habituadas a lidar com agências de cooperação estrangeiras se dispuseram a participar dos preparativos para Beijing. Outras, que estavam determinadas a manter a independência do movimento feminista das agências internacionais e do Estado, opuseram-se a qualquer envolvimento com a Conferência de Beijing. Ou seja, elas mantinham-se firmes na defesa da 'autonomia' do movimento - agora redefinida por muitas como revolvendo em torno das relações do feminismo com as arenas institucionais formais e a capacidade do movimento de definir suas próprias agendas, independentemente dessas instituições. Os debates em Costa del Sol também trouxeram de volta a discussão sobre o que era considerado por muitas como o papel perverso do financiamento estrangeiro no movimento, especialmente em vista da proliferação de ONGs patrocinadas por países do Norte, e do receio de que tal financiamento pudesse comprometer politicamente ou, pior ainda, vir a controlar a agenda feminista.

Aquelas que se recusaram a participar e decidiram verbalizar sua oposição a Beijing faziam parte da minoria. As outras se prepararam para participar do fórum das ONGs pelos dois anos seguintes, sob a direção e diretrizes do Fundo das Nações Unidas para as Mulheres (UNIFEM), que procurou promover grupos de trabalho em todos os países - apesar de muitas haverem questionado a transparência e a abertura dos métodos organizacionais aplicados. Os grupos patrocinaram vários Encontros nacionais, assembléias estaduais e sub-regionais, e um último Encontro regional, realizado em Mar del Plata, Argentina, em conjunto com a conferência preparatória regional oficial da Comissão Econômica para a América Latina e o Caribe (ECLAC), em setembro de 1994.

Embora uma discussão detalhada sobre o processo de Beijing esteja além do que nos propomos neste ensaio, tal processo teve, sem dúvida, um imenso impacto na política do movimento feminista e nas políticas de gênero por toda a América Latina e Caribe. ${ }^{29}$ Durante aproximadamente dois anos antes da Quarta Conferência Mundial de Mulheres, muitos dos esforços organizativos e de lobby do movimento foram absorvidos pelos preparativos locais, nacionais e regionais para Beijing. Recursos materiais e recompensas políticas consideráveis foram acumulados por aqueles setores do movimento - em grande parte, o número crescente de ONGs profissionalizadas e especializadas na advocacy de políticas - que dedicaram a maior parte de suas energias para influenciar os relatórios governamentais sobre a situação das mulheres e trabalharam para integrar as perspectivas feministas às plataformas de ação regionais e globais.

Dadas as suas origens em intercâmbios anteriores promovidos pelos Encontros, "não é surpreendente que a coordenação latino-americana e caribenha de ONGs para o FWCW

\footnotetext{
${ }^{29}$ Sobre o impacto local, nacional e regional dos preparativos e da participação das feministas latinoamericanas e caribenhas no processo preparatório para a Conferência de Pequim, ver Ana Maria AMADO, 1995; Laura ASTURIAS, 1995; Alda FACCIO, 1995; María Lis RODRÍGUEZ, 1995; VARGAS, 1996; ALVAREZ, 1998; Jean FRANCO, 1998; LEBON, 1998; Cecilia OLEA MAULEÓN, 1998; FRIEDMAN, 1999; e FRIEDMAN, HOCHSTETLER e CLARK, 2000.
} 
- sediada em Lima e encarregada de articular seis 'pontos focais' sub-regionais na região - declarou no seu slogan que Beijing iria servir como 'Texto e Pretexto' para os movimentos feministas da região". ${ }^{30}$ Ou seja, enquanto as feministas envolvidas esperavam influenciar os 'textos' reais dos relatórios governamentais e dos documentos da ONU, muitas viam Beijing como uma oportunidade excepcional, um 'pretexto', para remobilizar e revitalizar os movimentos feministas e promover debates públicos sobre a subordinação das mulheres. ${ }^{31}$ Um jogo dinâmico de texto e pretexto, então, orientou muito do envolvimento de ONGs feministas no processo da ONU e trouxe um número de conseqüências positivas para os discursos e práticas dos movimentos locais. ${ }^{32}$

Ainda, a participação no processo de Beijing forneceu a "relativamente poucas militantes nas arenas locais do movimento um maior acesso a um capital político, cultural e material". ${ }^{33}$ O envolvimento crescente de muitas ativistas na advocacia intergovernamental, portanto, às vezes "traduziu-se localmente em maneiras que exacerbaram os desequilíbrios de poder existentes entre ativistas e organizações", ${ }^{34}$ desestabilizando a solidariedade dentro dos movimentos e acentuando as desigualdades racial-étnicas, de classe e outras, entre as militantes. ${ }^{35}$

Com respeito ao capital político, por exemplo, as líderes locais dos grupos que participaram da conferência muitas vezes conquistaram um acesso maior aos espaços de políticas nacionais e tornaram-se as interlocutoras privilegiadas daqueles que elaboram políticas domésticas e das agências de cooperação internacionais. Quando financiaram o envolvimento da sociedade civil nos processos nacionais e regionais para Beijing, as agências claramente favoreceram "as ONGs feministas maiores, com mais recursos, e mais profissionalizadas, cujo trabalho possui uma relevância política considerável, sobre as organizações menores, menos formalizadas, tipicamente orientadas para as bases ou para a identidade e solidariedade". ${ }^{36}$ Finalmente, como a própria Virginia Vargas argumenta em um ensaio retrospectivo criterioso, 'o equilíbrio entre 'texto' e 'pretexto' não resistiu ao confronto do global com o local. [Localmente,] a ênfase no texto [...] prevaleceu, enquanto que as estratégias direcionadas para as transformações culturais, simbólicas e políticas [foram] deixadas em segundo plano" ${ }^{37}$ Além de agravar as tensões entre militantes e grupos centrados em políticas e aqueles mais centrados no movimento, então, o processo de Beijing deixou bastante claras as divergências políticas crescentes entre as feministas locais. Esses conflitos se concretizaram com uma virulência sem precedentes no Sétimo Encontro, em Cartagena, Chile.

\section{Cartagena, Chile, 1996}

A absorção de muito das energias do movimento pelo processo de Beijing forçou as organizadoras chilenas a adiarem o Sétimo Encontro para novembro de 1996. A partir de

\footnotetext{
${ }^{30}$ ALVAREZ, 2000, p. 43. Os pontos focais eram coalizões de ONGs de mulheres e ativistas individuais estabelecidas nas seguintes sub-regiões, designadas pela ONU: México, América Central, Caribe, Região Andina, Cone Sul e Brasil.

${ }^{31}$ Entrevista formal com Gina Vargas e Cecilia Olea Mauleón, conduzida por Sonia E. Alvarez (Virginia VARGAS e Cecília OLEA MAULEÓN, 1997).

${ }^{32}$ ALVAREZ, 1998 e 2000; VARGAS e OLEA MAULEÓN, 1998.

${ }^{33}$ ALVAREZ, 2000, p. 56.

${ }^{34}$ ALVAREZ, 2000 , p. 56.

${ }^{35}$ VARGAS e OLEA MAULEÓN, 1998; e FRIEDMAN, 1999.

${ }^{36}$ ALVAREZ, 2000, p. 57. Ver também ALVAREZ, 1999.

${ }^{37}$ VARGAS, 1998b, p. 14.
} 
maio de 1995, as ativistas chilenas realizaram vários Encontros nacionais para planejar o evento regional, e terminaram por descobrir que as diferenças e a má vontade entre as feministas engajadas em instituições formais e aquelas que defendiam a autonomia absoluta do movimento estavam crescendo. De fato, as chilenas identificadas com o Movimento Feminista Autônomo (MFA) local, que no final dominou o comitê organizador local para esse Encontro, deliberadamente provocaram o confronto entre essas duas tendências ou 'lógicas' no movimento. Ao apropriarem-se do termo autônomo, que, como argumentamos acima, historicamente era quase sinônimo de feminismo, tentaram marcar inequivocamente a diferença entre elas e aquelas que elas pejorativamente chamavam de as institucionalizadas, isto é, aquelas que trabalhavam 'dentro' de instituições governamentais e não-governamentais. ${ }^{38}$

No Chile, as autônomas emergiram como uma corrente política explícita em 1993, proclamando que suas 'irmãs' feministas - que haviam escolhido ocupar os novos 'espaços das mulheres' em partidos e no Estado, ou que haviam fundado ONGs profissionais - haviam 'institucionalizado' e vendido o movimento às forças do 'patriarcado e do capitalismo neoliberal', usando "o movimento como uma alavanca para conseguirem espaços de poder", em vez de trabalharem para "fortalecer o movimento". Ao explicar as origens de sua corrente autônoma, o MFA chileno defendia que:

A constituição do movimento feminista autônomo coincide com o processo no qual o feminismo situa-se, em geral, frente a uma definição de sua relação com o sistema. Em um período em que a ideologia do neoliberalismo está criando raízes [...] o feminismo não poderia permanecer nas margens desse predicamento histórico, e, portanto, duas correntes políticas tomaram um perfil definido. Uma, dirigida de dentro de instituições, é representada fudamentalmente pelas mulheres que trabalham para ONGs, cuja ideologia atende à ideologia neoliberal do pragmatismo do ponto de vista de gênero [...] e que tenta tornar invisível e suplantar o movimiento social de mujeres e o movimento feminista. A outra corrente, a autônoma, é aquela que "se posiciona na outra esquina", do ponto de vista do movimento e da importância do papel das mulheres, questionando os valores do sistema e das instituições. ${ }^{39}$

As divisões entre as feministas chilenas eram agudas, provocadas em grande parte pelas diferenças em como as militantes responderam ao Estado na era pós-Pinochet. ${ }^{40}$ Enquanto muitas prontamente alistaram-se em agências estatais sobre a mulher e na política formal sob a nova coalizão governista dos partidos Democrata Cristão e Socialista, outras criticaram veementemente aquilo que percebiam como a moderação injustificada da antiga agenda transformacional de oposição. Durante vários meses antes do Encontro, a polarização que separava os feminismos chilenos, que havia sido mais acentuada pelos preparativos nacionais para Beijing, tornou-se rapidamente 'transnacional' através da comunicação eletrônica e das revistas do movimento com uma circulação regional significativa, como Mujer/Fempress e Cotidiano Mujer, que publicaram vários artigos sobre os debates em torno da autonomia que no momento encontravam-se bastante acirrados entre as feministas chilenas. Em maio de 1996, o periódico Cotidiano Mujer, sediado em Montevideo, publicou uma carta assinada por 124 feministas chilenas denunciando a

\footnotetext{
${ }^{38}$ É importante observar, como foi explicado antes, que aquelas que esse termo pretendia descrever não o adotaram para si. Contudo, feministas na América Latina que rotineiramente se engajam em instituições formais são conhecidas como institucionalizadas, ou, menos pejorativamente, como institucionais.

${ }^{39}$ Sandra LIDID e Kira MALDONADO, 1996, p. 2.

${ }^{40}$ Sobre a dinâmica do movimento feminista chileno nos anos 1990, ver Alicia FROHMANN e Teresa VALDÉS, 1995; VALDÉS e Marisa WEINSTEIN, 1997; Elizabeth GUERRERO e Marcela RÍOS TOBAR, 1998; SCHILD, 1998; María Elena VALENZUELA, 1998; Tracy FITZSIMMONS, 2000; e Ríos TOBAR, 2000.
} 
manipulação do Encontro pelo MFA: "Nós declaramos que nem as condições nem as garantias necessárias para um Encontro aberto e democrático, como foram os anteriores, existem no Chile. As organizadoras organizaram um modelo no qual cada participante é definida de acordo com a sua concepção unilateral do que seja uma feminista". ${ }^{41}$ A carta pedia que um outro país assumisse o controle da organização o quanto antes. Uma outra carta, de autoria de Virginia Vargas, pedia às organizadoras dos seis Encontros anteriores para mediarem o conflito entre as chilenas e ajudarem a criar um espaço aberto ao diálogo democrático. No mesmo número, Margarita Pisano, uma das lideranças do MFA, respondeu, em uma entrevista, atacando as ONGs e redes feministas formalizadas, seu poder econômico, seu poder de definir a agenda, sua corrupção e sua falta de compromisso democrático. Ela percebeu como incoerentes a disposição de gastar grandes quantias nos preparativos para a viagem a Beijing e a falta de apoio ao Encontro no Chile.

Os debates cáusticos que precederam esse Encontro certamente não eram um bom sinal do que estaria por vir. Quando as 700 participantes começaram a chegar a Cartagena, uma pequena cidade operária perto de Santiago do Chile, as tensões estavam em alta. As organizadoras planejaram o Encontro em torno de três temas: "1) as estruturas políticas e filosóficas das diversas correntes do feminismo latino-americano: autonomia, movimento, ética feminista, as relações com o movimento de mulheres e as estratégias no contexto da globalização do neoliberalismo; 2) as dimensões escondidas e discriminantes do feminismo: as mulheres indígenas, as mulheres negras, as lésbicas, as pobres [...] em nós; 3) desenredar nossas estratégias. Como podemos mudar o mundo?". ${ }^{42}$

Os dois primeiros eixos foram apresentados em duas sessões plenárias organizadas de forma rígida, nas quais as apresentadoras leram seus posicionamentos - um formato que muitas entenderam como uma violação dos princípios organizacionais não-hierárquicos e participativos que, como observamos acima, haviam orientado todos os Encontros anteriores. Além disso, as apresentadoras se envolveram em uma demonstração raivosa de insultos, acusações, recriminações e ataques maldosos, um comportamento nunca visto antes em um Encontro, e triste de se presenciar para todas as participantes. O grupo boliviano autônomo e altamente teatral Mujeres Creando usou uma linguagem particularmente violenta, fazendo ataques pessoais e, depois que Vargas se pronunciou para a assembléia, mostrou uma faixa dizendo: "Cuidado! O patriarcado agora se veste como mulheres famintas pelo poder". Durante a tarde, estava previsto que as participantes se dividissem nos dois 'campos' demarcados pelas organizadoras - autónomas e institucionalizadas - a fim de discutirem os posicionamentos apresentados. Contudo, um terceiro agrupamento, que se recusou a se identificar com um dos dois campos, reuniu-se sob a denominação de ni las unas, ni las otras (nem umas, nem as outras). Em uma colocação elaborada durante essa oficina da 'terceira posição', da qual participaram cerca de 300 a 400 mulheres, as participante criticaram a ênfase excessiva nas políticas públicas por alguns setores do movimento e reforçaram que "nós precisamos avaliar nossas próprias práticas [...] e discutir como podemos revitalizar o movimento feminista em nossos países, reconhecendo sua fragilidade atual". ${ }^{43}$ Ao mesmo tempo, elas questionaram o essencialismo e a intransigência das autónomas, argumentando que "a autonomia não se trata necessariamente de possuir ou não formas de financiamento, não significa a ausência de um projeto ideológico, nem se trata da demonização das instituições". ${ }^{44}$ Ao contrário, a

\footnotetext{
${ }^{41}$ COIIDIANO MUJER, 1996, p. 3.

${ }^{42}$ COMISIÓN ORGANIZADORA..., 1996.

${ }^{43}$ DESDE 'NI LAS UNAS NI LAS OTRAS'..., 1998, p. 226.

${ }^{44}$ DESDE 'NI LAS UNAS NI LAS OTRAS'..., 1998, p. 226.
} 
autonomia foi definida como um compromisso individual e coletivo para se reivindicar espaços a partir dos quais se possa transformar as vidas das mulheres e a sociedade como um todo.

Em muitas ocasiões, enquanto insultos eram trocados por todos os lados, pareceu que Cartagena, o suposto "Encuentro del Diálogo", seria o último Encontro. Contudo, a maioria nos 'dois lados', inclusive aquelas que se declararam estar em 'nenhum dos lados', resolveram evitar um rompimento maior. Porém, a falta de diálogo significou, entre outras coisas, que Cartagena foi uma oportunidade desperdiçada de se analisar as conseqüências positivas e negativas do processo de Beijing para as políticas feministas nacionais e regionais. Em vez disso, o legado de Beijing contribuiu para a polarização das participantes e pairou como um fantasma sobre Cartagena.

\section{O "Último Encontro do Milênio": atritos permanentes, debates renovados e possibilidades emergentes em Juan Dolio, República Dominicana, 1999}

Muitas militantes temiam que a 'prova final' dividida e acirrada que foi Cartagena seria repetida no Encontro de Juan Dolio, em novembro de 1999. De fato, um bom número de feministas, particularmente aquelas denominadas de institucionalizadas (mesmo que elas não se identificassem assim), evitaram participar do Encontro. Contudo, como vai ficar claro a seguir, o Oitavo Encontro não simplesmente reproduziu as tensões antigas em torno da autonomia do movimento, inclusão e exclusão. Pelo contrário, o Encontro provou mais uma vez ser um espaço crítico transnacional, no qual 'antigos' atritos foram renegociados, senão 'resolvidos', onde as identidades feministas foram redesenhadas e onde os debates do movimento, alguns novos e outros antigos, foram redimensionados.

Apesar da ausência de algumas ativistas institucionalizadas que temeram uma reprise de Cartagena, o Oitavo Encontro reuniu aproximadamente 1.300 mulheres. De acordo com o programa distribuído no Encontro, o comitê organizador deliberadamente escolheu não enfocar pontos específicos, mas sim três linhas políticas de discussão, que deveriam ser amplas o suficiente para permitir uma análise do "patriarcado na sua complexidade e como um sistema": 1) "formas novas e antigas de dominação" enfrentadas pelas feministas; 2) a dinâmica do feminismo como um movimento social, especialmente com respeito a relações de poder entre as mulheres dentro do movimento; e 3) prospectos para a criação de alianças entre os movimentos feministas regionais baseadas no mínimo de valores e objetivos comuns.

Um quarto componente - não menos importante para as organizadoras - era o que elas chamaram de eje transversal (eixo transversal), que pretendia recapturar os elementos "culturais, simbólicos e relacionais" da prática feminista ${ }^{45}$ Essa abordagem metodológica, identificada como "escolha política", tinha o propósito de promover formas criativas, dinâmicas e inovadoras de interação entre as participantes. Cada participante deveria selecionar um de dez grupos, organizados em torno de 'dinâmicas' como teatro/ dramatização, poesia, dança/expressão corporal, colagem, pintura corporal, entre outras. Os resultados da interação de cada grupo deveriam ser apresentados nas duas sessões plenárias.

\footnotetext{
${ }^{45}$ De um "flier" intitulado "Información sobre la metodologia en el trabajo con los ejes políticos", distribuído pelo comitê organizador durante o Encontro.
} 
A importância igual dada a forma e conteúdo - assim como a arte e 'cultura' como espaços privilegiados na busca de novos modos de comunicação e de sociabilidade ficou também evidente na abundância de eventos culturais, que incluíram vídeo, teatro, dança e performances musicais, apresentados todas as noites. Esse eixo transversal foi desenhado para servir como um equalizador entre aquelas com diferentes capacidades e níveis de paciência para os modos verbais e analíticos sofisticados do trabalho do movimento, oferecendo uma variedade de opções de comunicação, expressão e participação. Aquelas que não queriam participar de nenhum dos dez grupos preestabelecidos podiam criar o seu próprio grupo (sem necessariamente seguir a metodologia proposta). Ao mesmo tempo, um programa 'paralelo' oferecia mais de 30 oficinas, grupos de discussão e outras atividades de iniciativa das próprias participantes.

\section{Feminismos corporais e expressivos}

O apelo por uma "nova ética feminista" estava embutido em uma forma de feminismo cultural, que, apesar de sempre estar presente nos Encontros, permeou a estrutura organizacional de Juan Dolio. Essa tendência era expressa através de uma ênfase no corpo, na expressão corporal e artística, no conhecimento do 'self' e na força interior, assim como uma ênfase nos valores das mulheres, nas experiências comuns enquanto mulheres e em um senso comum de força proveniente das histórias das mulheres $(\mathrm{el}$ ser mujer).

A forte presença de feministas culturais entre as organizadoras dominicanas, parte das quais se identificavam como autónomas, e a ausência relativa de feministas dominicanas mais interessadas em advocacy certamente reforçou essa tendência. Contudo, as escolhas metodológicas do comitê organizador eram também parte de uma estratégia que parecia ter o propósito de deslocar os debates políticos acirrados de Cartagena e de sarar as feridas daquele Encontro de tanta discórdia.

De fato, a metodologia escolhida foi bem-sucedida em aliviar as tensões. Os grupos pequenos certamente facilitaram a inclusão e possivelmente ajudaram na busca por estratégias comuns. Ainda assim, enquanto essa ênfase no corpóreo sobre o verbal ou analítico deleitou algumas participantes do Encontro, desconcertou outras. Por um lado, muitas que estavam participando pela primeira vez pareceram apreciar a oportunidade de conhecer outras participantes e se engajar em formas de auto-expressão, dentro de uma atmosfera que minimizava as diferenças de idade, a experiência feminista prévia e as tendências políticas. Por outro lado, algumas mulheres acharam a abordagem frustrante, porque ofereceu pouca orientação para a criação de estratégias sobre as condições políticas em transformação e resultou em pouco mais de uma lista de problemas ou questões apresentados na plenária final. Referindo-se com humor à abordagem da oficina da manhã como feminismo 'light', as mulheres que diziam querer 'discutir' em vez de 'tocar' seu feminismo formaram seus próprios grupos de discussão formais ou informais. O maior desses grupos, conhecido como o grupo discoteca por causa do seu local de encontro, atraiu dúzias de militantes de todas as idades e níveis de experiência para discutirem estratégias concretas para o movimento.

\section{Transpondo a separação entre autónomas e institucionalizadas?}

Além das tensões entre abordagens 'corporais' e mais 'cerebrais', o Oitavo Encontro marcou uma transição significativa no conflito entre autonómas e institucionalizadas. O Encontro de Juan Dolio revelou uma dissipação gradual desse conflito - um processo iniciado 
no desfecho do Sétimo Encontro em Cartagena e acentuado no 'Encontro autônomo', realizado em Sorata, Bolívia, em 1998.

Apesar da presença de um número significativo de autonómas que haviam participado do Encontro de Sorata, e do fato de que parte delas participou ativamente do comitê organizador dominicano, o Oitavo Encontro não terminou sendo mais um confronto entre dois setores polarizados do movimento. Esse Encontro, ao contrário, foi caracterizado pela diversidade e heterogeneidade das questões aventadas, em vez da predominância de discussões sobre uma única questão, e pela aparente falta de disposição das participantes de se envolverem em confrontos como aqueles acontecidos em Cartagena. Também parece que o próprio nível de animosidade demonstrado no Chile teve um efeito imprevisto no imaginário coletivo feminista latino-americano: impôs a necessidade de cicatrizar as feridas e de exorcizar o trauma, sentido por muitas feministas, provocado pelo Sétimo Encontro.

Além disso, Cartagena indiscutivelmente produziu uma tensão em nível regional entre autónomas e institucionalizadas que não encontrou um correspondente direto na maior parte dos outros países senão o Chile - com exceção, em parte, da Bolívia, da Argentina e, talvez, do México. Ainda assim, o 'novo' debate sobre autonomia encenado no Chile foi revivido em muitos países durante a segunda metade dos anos 1990 - trazendo à tona preocupações já existentes, apesar de às vezes ainda não articuladas completamente, sobre a 'institucionalização' excessiva do movimento. Nesse sentido, os Encontros mais uma vez serviram como um espaço vital de mediação entre as arenas locais/nacionais e internacionais do movimento.

Em retrospecto, fica difícil falar de um confronto real em um conflito que se desenvolveu como uma crítica unilateral por parte das autónomas, mas nunca teve um interlocutor organizado para defender a posição oposta, as chamadas institucionalizadas. Desde o início dos anos 1990, esse grupo estava cada vez mais ausente das esferas do movimento nas quais as autónomas concentravam suas ações. Ao contrário, elas preferiam evitar ou ignorar as críticas e questões colocadas pelas autónomas, e se concentraram no fortalecimento das estratégias de luta por políticas feministas. As feministas que reconheceram as autónomas como interlocutoras legítimas foram precisamente aquelas que não se identificavam com o cenário dicotômico que as autónomas tentavam construir. Eram, em geral, ativas nas 'esferas do movimento', enquanto ao mesmo tempo contribuíam em outros processos promovidos por canais mais 'institucionais', como ONGs. No final das contas, muito poucas feministas se dispuseram a defender uma estratégia puramente institucional para levar adiante uma agenda feminista.

À medida que novas questões e atores surgiram no movimento, e à medida que o contexto no qual se originou o conflito entre autónomas e institucionalizadas mudou, a lógica do confronto construída em torno desse eixo parecia chegar a um estágio de exaustão inevitável. Por exemplo, enquanto, como sugerimos acima, a Conferência de Beijing assombrou a discussão em Cartagena, em Juan Dolio essa questão havia se transformado em um 'elefante branco' - algo que todas agora 'viam' claramente, mas sobre o qual já tinha sido dito o suficiente. Conflitos internos entre as próprias autónomas também contribuíram para que perdessem visibilidade e poder dentro do movimento e para a conseqüente dissolução do conflito. A experiência em Sorata, Bolívia, durante o primeiro, e até então o único autoproclamado Encontro Feminista Autônomo, teve um efeito devastador na capacidade das autónomas de se organizarem e de agirem como uma corrente política unificada. O evento, ironicamente, foi repleto de confrontos com respeito a quem poderia ser considerada uma feminista autônoma 'genuína'. A participação de mulheres mais jovens e a circulação de interpretações diferentes sobre o signifiçado 
da autonomia para o feminismo estavam entre as questões mais conflituosas. Essa experiência, juntamente com a fragmentação entre grupos de autónomas em países diferentes, traduziu-se em um claro enfraquecimento de seus posicionamentos mesmo antes do Oitavo Encontro. Isso se tornou aparente no grupo de trabalho que as autónomas organizaram em Juan Dolio, independentemente do programa oficial, que nunca conseguiu reunir mais de 30 mulheres de uma só vez.

Apesar de a corrente das autónomas nunca ter sido homogênea internamente, foi dividida mais ainda por conflitos internos. Portanto, não se pode mais falar em um discurso ou corrente autónoma unificada e coerente. ${ }^{46}$ Essa fragmentação explica em parte por que, apesar da influência das autónomas no comitê organizador local, elas não conseguiram exercer um papel predominante em Juan Dolio. Como discutimos acima, as organizadoras do Oitavo Encontro tomaram uma decisão política explícita de evitar confrontos. A metodologia do Encontro foi duramente criticada pelas autónomas que participaram, que levantaram a acusação de se tratar de uma estratégia para apagar o Encontro de Cartagena da memória histórica do feminismo, em uma tentativa de ignorar diferenças reais e importantes entre as feministas.

Finalmente, os processos de introspecção crítica em que muitas feministas, que centraram seus esforços principalmente na advocacy de políticas nos últimos anos, embarcaram também parecem ter contribuído para a dissolução desse conflito. Mesmo que não seja um fenômeno difundido, um número pequeno, mas significativo, de históricas que formam parte da 'ala de advocacy' do movimento participou do Oitavo Encontro, demonstrando disposição para refletir criticamente sobre seu ativismo nos anos 1990. Algumas admitiram a necessidade de se avaliar os perigos de uma estratégia política baseada apenas na defesa de políticas e nas negociações com governos e organizações internacionais, e direcionada primordialmente para influenciar a construção de agendas políticas ou institucionais. Muitas admitiram, por sua vez, a legitimidade de algumas das críticas feitas pelas autónomas. A fragmentação e o enfraquecimento do posicionamento das autónomas, juntamente com uma crescente autocrítica por parte de muitas das chamadas institucionalizadas, facilitaram a dissolução do conflito entre essas correntes.

Em Juan Dolio, no entanto, tornou-se evidente que muito do discurso e das críticas das autónomas havia repercutido entre várias feministas latino-americanas e caribenhas. Elas conseguiram colocar questões centrais na agenda e forçaram um debate importante sobre os custos e benefícios de estratégias feministas nacionais e internacionais 'institucionalmente centradas', que, do contrário, teriam passado intocadas. A esse respeito, o Oitavo Encontro se situou em uma intersecção entre os conflitos manifestados em Encontros anteriores e o que pode ser esperado do movimento no futuro. Enquanto no Chile o Encontro girou em torno do confronto entre duas estratégias políticas supostamente opostas, o Encontro dominicano não apresentou uma única questão central em torno da qual as

\footnotetext{
${ }^{46}$ Ao contrário, existem muitas vozes e propostas. Margarita Pisano explica que a corrente é composta de pelo menos três tendências principais: uma, intimamente ligada a um tipo de "feminismo cultural", à qual muitas das organizadoras de Juan Dolio aderiram; uma outra, identificada com um discurso de classe mais forte, onde se encontram hoje muitas ex-militantes da "ultra-esquerda" - um grupo que tem demonstrado laços significativos com grupos de mulheres populares; e, finalmente, um terceiro grupo que se identifica como as autónomas "puras", que se reúnem em torno de algumas das figuras históricas mais proeminentes dentro dessa linha de pensamento, e que estão distanciadas tanto do feminismo cultural como de um discurso puramente de classe (RÍOS TOBAR, Lorena GODOY e Elizabeth GUERRERO, 2002. Membros deste último grupo têm funcionado como ideólogas para as autónomas e têm sido incapazes de se engajar em qualquer tipo de diálogo político significativo com outras feministas de posições políticas ou ideológicas diferentes.
} 
feministas se posicionaram, mas, pelo contrário, forneceu um solo fértil para o florescimento de uma variedade de questões.

\section{Ultrapassando fronteiras de geração: a emergência de um movimento feminista jovem e a renegociação da identidade e do poder}

Enquanto sempre tem havido coortes políticas distintas nos feminismos latinoamericanos, a presença articulada de uma nova geração de feministas nesse Encontro marcou uma mudança na segunda onda dos movimentos na região. O número crescente de feministas jovens em vários países propulsionou a proliferação de organizações compostas na sua maioria de mulheres dessa nova geração, como o Colectivo Feminista Bajo Sosphecha (Coletivo feminista 'sob suspeita') no Chile, que se formou em resposta à divisão entre autónomas e institucionalizadas no movimento feminista chileno. O coletivo tentou se organizar acima dessa divisão política, apesar de muitas trabalharem em ONGs. No México, um movimento emergente vem operando desde o final dos anos 1990, culminando com o Primeiro Encontro Nacional de Jovens Feministas em 1998. ${ }^{47}$ A formação dessa geração de feministas, na sua maior parte jovens de centros urbanos, foi influenciada pela revolução zapatista de 1994, pelo movimento estudantil e pelos programas de estudo da mulher nas universidades, como documentado por publicações como a Lunatika (feminismo, política, sexualidade, cultura), "uma publicação de mulheres jovens para mulheres". ${ }^{4}$

Com a presença crescente de jovens feministas no Oitavo Encontro, um avanço importante nesse Encontro foi a articulação da perspectiva dessa nova geração na declaração (Declaración de las jóvenes feministas) que elas apresentaram na plenária final. Resultante da oficina "Mulheres jovens no final do século", reunida pelo Bajo Sospecha e com a participação de mais de 50 mulheres, o manifesto clamava por um maior reconhecimento daquelas que entraram no movimento feminista nos anos 1990. Chamando a atenção para sua crescente participação nos grupos de trabalho e nas plenárias, elas viram o Oitavo Encontro como um marco da visibilidade das mulheres jovens dentro do movimento. Ao tempo em que reconheciam serem beneficiárias dos ganhos assegurados pelas gerações anteriores, elas criticaram a falta de abertura em outros espaços do movimento e a ausência de estratégias para envolver novas ativistas.

Uma intervenção decisiva das jovens feministas foi a alegação de que "o feminismo é definido por sua prática e poder", desafiando as feministas a examinar as relações internas de poder nas organizações do movimento. Extremamente críticas quanto à maneira em que feministas mais antigas falharam em compartilhar o poder, elas denunciaram uma divisão do trabalho em que "algumas feministas escrevem, pensam e falam, enquanto outras tiram fotocópias, distribuem panfletos, e formatam textos. [...] Para nós, isso parece corresponder a práticas patriarcais de fazer política que resultam no estabelecimento de hierarquias, na invisibilização de algumas e na exclusão de outras". ${ }^{49}$ A declaração foi um chamado para o diálogo e uma exigência de reconhecimento de uma geração mais

\footnotetext{
${ }^{47}$ Entrevista com Alexandra Ancheita, organizadora da conferência da juventude feminista e membro do grupo editorial da Lunatika, conduzida por Maylei Blackwell , em 15 de março de 1999, gravação em cassete, escritórios do K'inal Antsetik, Cidade do México (ANCHIETA, 1999).

${ }^{48}$ Coordenada por Norma de la Cruz, Lunatika pode ser contatada através do seguinte endereço: Vicente Suárez 146-12 Col. Romz, México D.F., C.P. 06140 ou através do e-mail lunatikamex@yahoo.com.

${ }^{49}$ DECLARACÍON... , 1999.
} 
jovem de feministas, emergindo de circunstâncias históricas, econômicas e políticas diferentes. Como filhas da 'década perdida' dos anos 1980, que cresceram sob regimes autoritários, no meio de conflitos armados e crises econômicas, elas testemunharam o colapso de visões utópicas de transformação social e uma crise no sistema dos partidos políticos, assim como a revalorização da democracia. Mesmo reconhecendo que a luta das feministas de gerações anteriores conquistou mais espaços para as mulheres, as jovens ativistas observaram que a sua geração de feministas amadureceu em um mundo marcado pela globalização, pelo desenvolvimento tecnológico e pelo neoliberalismo, em que as formas de opressão com as quais elas se confrontam são geralmente mais brutais economicamente, mesmo que socialmente mais sutis - fatores que distinguem suas experiências daquelas de gerações passadas.

Em grande parte, essa nova geração de militantes surgiu dos espaços institucionais conquistados pelo feminismo - como ONGs e programas universitários de estudos da mulher - e não dos movimentos de massa mais radicais ou partidos políticos nem da antiga Esquerda; de fato, algumas expressaram um sentimento de perda por não haverem testemunhado a militância feminista e as mobilizações das massas dos 'dias de ontem'. Além disso, essa diferença de gerações nas trajetórias políticas também pode permear o desejo expresso dessas jovens mulheres de não repetir os erros do passado, como "conflitos internos que surgiram nas raízes da relação com o Estado e com outros atores políticos". Como um setor novo e distinto do movimento, cujos interesses são normalmente negligenciados pela agenda feminista "central", as jovens feministas também articularam uma crítica dos discursos da diversidade e do pluralismo, argumentando que "geralmente a idéia de diversidade implica mais precisamente diferença e desigualdade [...] e não permite o reconhecimento ou a legitimação dos/as outros/as e de suas experiências". ${ }^{50}$

\section{Discursos da diversidade}

A visibilidade maior das mulheres jovens em Juan Dolio indicou que, na virada do novo século, as tensões persistentes entre os feminismos latino-americanos e caribenhos acerca de questões de inclusão coincidiram com o conflito recorrente do movimento sobre a questão da expansão. Inclusão não era mais uma questão de como lidar melhor com as 'Outras' do feminismo - ou seja, mulheres negras das favelas ou militantes de grupos de mulheres populares. O Encontro de Juan Dolio deixou muito claro que as 'Outras dos feminismos' estavam agora ativamente reinventando 'outros feminismos' - reimaginando a 'comunidade feminista' da região, que desse conta da sua expansão e ressignificação entre as 'feministas populares', feministas afro-latino-americanas, jovens feministas, feministas lésbicas, etc. De fato, a história dos Encontros pode ser lida como uma história de conflito e debate sobre as maneiras em que raça, etnia, classe e orientação sexual são eixos organizadores da opressão de gênero e definem como gênero é experienciado na vida cotidiana.

Dada a relação histórica da segunda onda do feminismo com a Esquerda, uma crítica de classe da opressão feminina assim como um posicionamento estridentemente antiimperialista têm sido evidentes nos Encontros regionais desde Bogotá. Durante a primeira década dos Encontros, contudo, pouquíssima atenção foi dada à forma como as identidades de gênero e a estratificação social são determinadas não apenas por classe e gênero, mas também por raça e etnia, sexualidade e outros vetores de poder que dão forma à subordinação das mulheres.

$50 \ldots, 1999$. 
Como a feminista peruana Maruja Barrig sugere, as origens da segunda onda do feminismo na Esquerda fizeram-nas "tributárias de uma tradição marxiana de interpretação da nação que subsumiu o étnico-cultural sob categorias rígidas de proletários, camponeses e estudantes", o que "cegou" a maioria das ativistas brancas/mestiças para as desigualdades de raça e etnia entre as mulheres. ${ }^{51}$ Apesar da falta de discussão sobre raça desde o início, Sergia Galván observa que as mulheres negras têm participado dos Encontros e se reunido desde 1983: "A questão étnica/racial tem encabeçado a lista de nós e ausências na agenda do feminismo latino-americano, apesar do fato de que, a partir de 1983, as mulheres negras presentes nos Encontros tentaram abrir espaços nas agendas; contudo, é claro que [fazemos isso] da periferia e de uma posição minoritária, onde nos sentimos com a obrigação de agir dessa forma. As mulheres indígenas têm feito o mesmo nos últimos dois Encontros [em 1990 e 1993]". 52

As mulheres negras que participaram do Quinto Encontro na Argentina decidiram realizar um próprio Encontro regional para refletirem sobre suas experiências organizacionais dentro do movimento feminista e dos movimentos negros nacionais no Uruguai, Brasil, Equador, Colômbia, Panamá, Porto Rico e República Dominicana. Em julho de 1992, elas organizaram o Primeiro Encontro de Mulheres Negras da América-Latina e do Caribe, realizado na República Dominicana, onde 350 negras de 32 países se reuniram durante seis dias de intenso diálogo, elaboração de estratégias e confraternização.

Desde então, a diversidade de actoras e lutas feministas vem sendo cada vez mais reconhecida dentro dos Encontros, mas não sem debates substanciais e negociações. Por exemplo, apesar de as feministas lésbicas sempre terem sido centrais nos movimentos feministas e de mulheres por toda a região, elas tiveram que lutar para incluir a questão da orientação sexual na agenda feminista; tudo isso apesar do fato de que, nos Encontros, os grupos de trabalho sobre questões lésbicas estão entre os mais concorridos, onde as participantes chegam a ocupar os corredores. Para confrontar a invisibilidade dentro do movimento, elas organizaram uma Rede de Feministas Lésbicas da América-Latina e do Caribe. Feministas lésbicas se reuniram em um Encontro regional independente em 1987, imediatamente antes do Quarto Encontro em Taxco, e desde então têm se encontrado em diversas outras ocasiões. ${ }^{53}$

Ao passo que os diálogos em Juan Dolio revelaram que a diversidade era vista agora como um ideal positivo pela maioria no movimento, as diferenças e desigualdades sociais, econômicas, históricas e culturais entre as mulheres não foram abordadas de frente no Oitavo Encontro. Isso ficou muito mais evidente na tendência das participantes de fundir ou confundir a diversidade ideológica com as diferenças sócio-econômicas, culturais, raciais e sexuais. Como geralmente ainda é o caso entre os feminismos nos Estados Unidos, a redução das diferenças para uma forma de pluralismo feminista faz parecer que todos os feminismos e feministas funcionam igualmente no mesmo terreno social e não reconhecem como esse terreno é fraturado por desigualdades sociais e econômicas profundas e por diversas formas de preconceito.

Essa negligência relativa com as desigualdades entre as mulheres - mesmo quando se celebrava a 'diversidade' feminista - foi agravada pela busca contínua de um "mínimo denominador comum" em Juan Dolio. Uma facção no Encontro insistia em que o movimento feminista criasse uma estratégia comum - ao que outras responderam: "nós somos um

\footnotetext{
${ }^{51}$ BARRIG, 2001b, p. 20.

${ }^{52}$ GALVÁN, 1995, p. 34

${ }^{53}$ Norma MOGROVEJO, 1998 e 2000.
} 
movimento, não um partido". Enquanto algumas expressaram um certo temor de que as muitas diferenças terminassem por descentrar os interesses do feminismo histórico ou fragmentar o movimento, muitas das sessões, grande parte no programa paralelo, enfocaram novas estratégias, como o grupo sobre Estrategias para incidir desde el feminismo para combatir el racismo y el sexismo. As lésbicas também organizaram diversas sessões e realizaram suas próprias reuniões políticas ad hoc, onde idéias, estratégias e depoimentos foram compartilhados.

Apesar desse crescente reconhecimento da 'diversidade', as mulheres indígenas estavam numericamente invisíveis no Oitavo Encontro, muito embora elas tenham emergido como uma força internacional significativa na organização das mulheres na região na última década. Um único grupo de trabalho, apropriadamente intitulado La identidad india 'invisible': un racismo feminista, destacou sua ausência das estratégias e agendas formuladas no Encontro. A geografia pode ter sido um fator responsável pela relativa ausência de mulheres indígenas, já que sua participação em Encontros anteriores foi mais visível em sub-regiões ou países onde havia uma maior mobilização em torno da causa indígena. Um segundo fator foi a expansão da organização independente de mulheres indígenas em nível continental.

Mesmo que mulheres indígenas tenham participado de Encontros anteriores, o Quinto Encontro na Argentina marcou uma transição visível, à medida que mulheres indígenas organizaram seu próprio grupo de trabalho para discutir a oposição à comemoração dos 500 anos da suposta descoberta das Américas por Colombo, e propuseram que o dia 11 de outubro fosse proclamado o Dia das Mulheres Indígenas. Se os Encontros facilitaram redes como a Rede Lésbica Feminista ou a de Mulheres Negras, podemos argumentar que as redes regionais de mulheres indígenas foram formadas em parte como uma conseqüência de desencuentros. No entanto, diferentemente de outras redes regionais, a organização das mulheres indígenas ocorreu em uma cojuntura em que um movimento indígena internacional estava crescendo; assim, mesmo tendo zonas de contato tanto com o movimento feminista quanto com o movimento de mulheres mais amplo, desenvolveu sua própria estrutura independente.

De fato, o processo preparatório para Beijing, e não os Encontros feministas da América Latina, forneceu o catalisador para os Encontros regionais regulares das mulheres indígenas. ${ }^{54}$ No Encontro preparatório para Beijing em Mar de Plata, as mulheres indígenas ficaram incomodadas por sua falta de representatividade e pelo fato de uma 'conselheira', não escolhida por elas próprias, ter sido designada para lidar com suas questões. Como conseqüência, elas decidiram que precisavam de seu próprio espaço para deliberar sobre como iriam participar do processo de Beijing, convocando o Primeiro Encontro Continental de Mulheres Indígenas das Primeiras Nações de Abya Yala (continente da vida), em agosto de 1995, em Quito, Equador. Nesse Encontro histórico, a Coordinadora Continental de Mujeres Indígenas se formou como a primeira rede de organizações de mulheres indígenas cobrindo toda a América do Norte, Central e do Sul. O Segundo Encontro Continental de Mulheres Indígenas aconteceu na Cidade do México, em 1997. O Terceiro Encontro foi realizado no Panamá, em março de 2000, e um Quarto Encontro aconteceu no Peru, em 2003.

\footnotetext{
${ }^{54}$ Para mais informação sobre a organização das mulheres indígenas na região, ver especialmente os capítulos 3 e 5 em Maylei BLACKWELL, 2000.
} 


\section{Redimensionando a exclusão: "racismo cultural" e diversidade lingüística em Juan Dolio}

Apesar de o Oitavo Encontro ter sido marcado por uma ausência quase total de mulheres que se identificavam como indígenas, a presença de centenas de mulheres afro-latinas dos Estados Unidos e mulheres negras do Caribe espanhol e de diversos países da América do Sul excederam de longe suas participações em Encontros anteriores. Como o primeiro Encontro a se realizar no Caribe, a reunião de Juan Dolio łambém lançou novas luzes sobre os debates feministas correntes sobre diversidade, dada a especificidade histórica, cultural, lingüística e demográfica daquela região.

Tensões políticas e dificuldades lingüísticas vieram à tona no Encontro de Juan Dolio. Foram propulsionadas pela proximidade da República Dominicana com o Haiti e seu antagonismo racial histórico com esse país - a primeira (e única) república predominantemente negra nas Américas, criada após a conquista da independência da França, há duzentos anos. De fato, várias militantes caribenhas chamaram a atenção para o fato de que uma manifestação dos abusos contra os direitos humanos sofridos rotineiramente por trabalhadores haitianos migrantes estava acontecendo precisamente no período do Encontro: a expulsão à força de trabalhadores 'desnecessários' da República Dominicana independentemente da sua situação como imigrantes. Uma feminista dominicana veterana argumentou que, devido às persistentes tensões entre os dois países, as mulheres haitianas participando do Encontro "deveriam ter sido tratadas com guantes de seda (luvas de seda)". Ao contrário, formas de exclusão que costuraram inextricavelmente questões de raça e as diferenças lingüísticas destacaram a hegemonia das mulheres hispânicas, que, em grande parte, se identificavam como de descendência européia ou mestiça, apesar dos protestos de suas 'irmãs' de idioma francês e inglês, que se identificavam como de ascendência africana.

O Oitavo Encontro parece haver exacerbado, ou, pelo menos, não ajudado a superar, algumas das divisões entre as feministas caribenhas anglófonas e francófonas e as dominicanas. Em uma entrevista, a veterana feminista dominicana Sergia Galván confirmou que o número de mulheres caribenhas participando do Encontro era decepcionantemente baixo e atribuiu isso a uma tendência histórica do feminismo dominicano de olhar para o resto da América Latina em vez do Caribe: "Desde o primeiro Encontro Feminista, nós temos enfatizado a necessidade de construirmos espaços onde as feministas caribenhas possam desenvolver elos, e agora que o Encontro está acontecendo na República Dominicana, no Caribe, [as feministas caribenhas] são minoria, o que reflete não apenas problemas de comunicação entre nós, como também uma falta de entendimento do que nós somos enquanto caribenhas". ${ }^{55}$

Essas tensões atingiram o ápice durante as sessões plenárias, onde, originalmente, apenas traduções improvisadas por voluntárias sem microfone aconteciam nos cantos da sala. Isso levou, durante a primeira plenária, à retirada em massa da delegação haitiana - que só pode ter interpretado esse acontecimento como um incidente de racismo cultural - e aos chamados calorosos para que a delegação retornasse por parte do resto das participantes. Daí por diante, voluntárias fizeram tradução simultânea em francês, inglês e português, com microfones. Porém, a tradução era abafada pelas conversas paralelas desrespeitosas daquelas que não precisavam dela, e, mais adiante, a tradução foi limitada ao francês por questão de tempo.

${ }^{55}$ GALVÁN, 1995. 
O efeito restritivo do uso hegemônico do espanhol sobre a participação de mulheres não falantes da língua não foi nada novo (especialmente para as falantes de português). Contudo, isso foi muito acentuado em Juan Dolio, como resultado das relações geopolíticas entre o Haiti e a República Dominicana, e a inevitável conjunção de questões de raça e língua nessa situação, assim como a contínua falta de uma discussão consistente sobre o racismo em Juan Dolio. A necessidade de se examinar questões de raça e outras questões da diversidade de maneira mais aprofundada em Encontros futuros foi colocada em um manifesto lido por um grupo de mulheres de ascendência africana, nas quatro línguas faladas no Encontro. Finalmente, a presença e o discurso de mulheres da diáspora latinoamericana e caribenha, com uma sensibilidade aguçada para as questões do racismo e da migração, e, conseqüentemente, para a condição das imigrantes haitianas na República Dominicana, certamente atiçaram a fogueira das discussões.

\section{Mulheres da diáspora latino-americana e caribenha nos Estados Unidos e na Europa}

Como testemunhos vivos de uma comunidade 'latino/a americana', cada vez mais interdependente e historicamente transnacional, um número sem precedentes de mulheres de origem latino-americana e caribenha, vivendo como imigrantes ou exiladas nos Estados Unidos (particularmente mulheres dominicanas e porto-riquenhas da Costa Leste) participou do Encontro. Como conseqüência, as fronteiras geográficas da comunidade feminista latino-americana imaginada foram dramaticamente remapeadas no Encontro de Juan Dolio. Enquanto um bocado de latinas dos Estados Unidos e da Europa havia participado desde o Primeiro Encontro e ainda eram vistas como 'participantes estrangeiras' pelas organizadoras do Quarto Encontro no México, em 1987, centenas delas participaram do Encontro de Juan Dolio. ${ }^{56}$ Além disso, o programa do Oitavo Encontro incluiu, pela primeira vez, inúmeras sessões dedicadas a questões - tais como o direito das imigrantes e racismo - enfrentadas pelas mulheres da diáspora latino-americana e caribenha. Mulheres afrocaribenhas dessa diáspora, juntamente com muitas 'brancas' e mestiças chicanas/latinas, que nas formações raciais nos Estados Unidos e na Europa são, evidentemente, politicamente situadas como não-brancas ou "de cor", geralmente se juntavam às mulheres de ascendência africana residentes na América Latina e no Caribe para chamar a atenção para as formas nas quais o racismo influencia profundamente a experiência $e$ as oportunidades de vida das mulheres, desafiando as feministas euro-latino-americanas e mestiças a não apenas 'abraçar a diversidade', mas também enfrentar a desigualdade entre as mulheres.

As latinas dos Estados Unidos conduziram vários grupos de trabalho em Juan Dolio, inclusive um sobre os mitos e as realidades das vidas das imigrantes nos Estados Unidos, intitulado Transgresión de Fronteras. O grupo de trabalho, organizado pelas militantes dominicanas e porto-riquenhas da região da cidade de Nova lorque, incluiu uma psicoterapeuta, uma assistente social, uma ativista contra a violência doméstica e a chefe de uma organização de avós que criam seus netos (geralmente devido a problemas de violência doméstica, incesto, prisão ou abuso de drogas por parte dos pais). Um de seus maiores objetivos era dissolver o mito de uma vida fácil das mulheres imigrantes nos EUA, tendo em vista, particularmente, as condições cada vez piores em cidades como Nova

\footnotetext{
56 ALVAREZ, 2000, p. 34.
} 
lorque, cortes na assistência social e restrições à imigração. Elas também queriam que as mulheres de outras localidades soubessem que elas estavam se organizando para abordar os problemas das comunidades de imigrantes e para estabelecer alianças entre fronteiras.

\section{Uma consciência maior dos efelitos locais da globalização e do neoliberalismo}

Enquanto as questões de classe têm sido sempre centrais nos feminismos da região, a rápida acentuação das desigualdades originadas na expansão do capitalismo neoliberal e os resultados complexos da globalização trouxe a exploração econômica, e sua intersecção com gênero e raça, ao centro de muitos debates no Oitavo Encontro. Muitas participantes forneceram evidências da complexidade da opressão econômica nas vidas das mulheres da região, especialmente das mulheres pobres das cidades e da zona rural, que são afetadas com mais força pela reestruturação econômica, e enfatizaram repetidamente a necessidade de uma reação das feministas. Apesar de o formato e a metodologia do Encontro não permitirem uma análise sistemática das mudanças econômicas, nem a elaboração de respostas coletivas, pareceu haver uma concordância substancial sobre a sua importância e suas implicações.

Por um lado, muitas participantes argumentaram que as políticas neoliberais aceleraram a pobreza das mulheres e aumentaram o fardo de suas 'jornadas duplas ou triplas' através da transferência simultânea de serviços públicos para o lar e do aumento da necessidade das mulheres de terem atividades remuneradas fora de casa. Cortes no financiamento público e a dependência dos caprichos do mercado acentuoaram uma cultura do individualismo, da competição e do conflito em torno de recursos escassos, tornando difícil a busca de soluções coletivas para os problemas sociais e a execução efetiva de direitos conquistados depois de muitas lutas na década anterior. Projetos de desenvolvimento passaram a enfocar formas de ensinar às mulheres a lidarem com a pobreza individualmente, em vez de mobilizá-las coletivamente para reduzir a pobreza em nível social. Mesmo projetos com objetivos comuns competem entre si por financiamentos de fontes internacionais, e agendas locais são normalmente prejudicadas para se adaptarem a prioridades externas. No mundo neoliberal de 'projetos' de mudança social, perspectivas de mudança a longo prazo têm sido freqüentemente substituídas por 'resultados' práticos a curto prazo.

Muitas insistiram, por outro lado, que a globalização também apresenta novas oportunidades para a organização feminista. Por toda a América Latina e todo o mundo, a revolução tecnológica nas comunicações possibilita a algumas feministas trocarem informação, escreverem e assinarem manifestos, planejarem conferências, elaborarem estratégias de ação política e compartilharem sonhos de novas utopias sem os obstáculos da distância geográfica. Ao mesmo tempo, contudo, a conexão ao global pode levar a uma certa desatenção, ou a uma interpretação distorcida das condições locais. Além disso, um acesso desigual aos recursos tecnológicos, tais como correio eletrônico e a Internet, pode exacerbar as desigualdades preexistentes e as práticas de exclusão.

Sem dúvida, os efeitos do neoliberalismo e da globalização colocam uma imensidade de questões estratégicas. "Como", perguntou uma participante, "devemos navegar num mundo onde tanta coisa mudou?" Outras destacaram a necessidade de ir além das críticas do que existe, para formular propostas concretas de mudança (de la queja a la propuesta) [da reclamação à elaboração de propostas]. Outras ainda enfatizaram a necessidade de se desenvolver modelos alternativos de globalização e de se aprender "graus de negociação" diante do restante da sociedade civil e de outros 
movimentos sociais que as permitam negociar uma posição ética entre la política de lo posible y la transgresión (entre a políica do possível e a transgressão). Refletindo esse maior engajamento das feministas com as desigualdades político-econômicas globais, as organizadoras do Nono Encontro Feminista Latino-Americano e Caribenho, realizado em Playa Tambor, Costa Rica, em dezembro de 2003, designaram como o tema central do Encontro a "Resistência ativa contra a globalização".

\section{Reflexões finais}

Os Encontros, como os próprios feminismos, são espaços não só de solidariedade e expansão, mas também de conflito e de exclusão, de negociações e renegociações. Essa dinâmica não se dá em um vácuo, mas sempre reflete o contexto de mudanças políticas e econômicas no qual os feminismos se desenvolvem. Desde o início dos Encontros, o quadro político da América Latina transformou-se dramaticamente, de um período em que as ditaduras e a repressão políica explícita floresciam em uma época em que quase todos os países do continente alegam ser democracias, de jure senão de fato. Enquanto a crise econômica parece caracterizar todo esse período, modelos de desenvolvimento também foram transformados, saindo de um modelo controlado pelo Estado para um capitalismo de mercado ou neoliberal, dentro de uma arena cada vez mais globalizada. Essas transições contextuais, por sua vez, deram uma nova forma às escolhas que diferentes feministas fizeram para interagir com atores e instituições fora do movimento feminista, sejam esses movimentos de Esquerda, partidos, agências estatais, financiadores internacionais ou os movimentos de mulheres mais amplos, em toda a sua diversidade.

Essas interações têm sido permeadas pelos significados, em constante mudança e continuamente contestados, de autonomia, que, por sua vez, geraram critérios instáveis de inclusão e exclusão na comunidade feminista regional imaginada. Do que as feministas devem ser independentes? Dos partidos? Do Estado? De outros movimentos de mulheres? Das fundações? E quem pode ser aceita como 'feminista': faveladas? Latinas gringas? Institucionalizadas?

Talvez, porém, o mais importante para os dois grupos de critérios seja quien decide? - quem decide? A resposta tem se tornado cada vez menos clara, à medida que as 'Outras' dos feminismos articulam 'outros feminismos' - e, além disso, insistem que reconhecer a diversidade, apesar de necessário, não é uma resposta suficiente para que se leve a desigualdade a sério. Ao contrário, o trabalho difícil de expor as desigualdades reais de poder e privilégio, sejam elas geradas por classe, raça/cultura, identidade sexual, lugar ou idade, deve fazer parte das análises e prescrições feministas.

Essas não são questões novas para aquelas engajadas na teorização e na prática feministas dentro e fora da região latino-americana. Contudo, analisar os processos de negociação nos últimos 20 anos, no contexto rico dos Encontros e de espaços similares transnacionais do movimento, pode nos fornecer novos insights sobre os debates acerca da fragmentação pós-moderna, tão celebrada por algumas e lamentada por outras dentro da comunidade feminista internacional.

Como participantes e analistas dos Encontros, nós também negociamos diferenças interpretativas, políticas, disciplinares e de geração no processo de escrita deste ensaio. E nós também aprendemos muito com as tensões que inevitavelmente surgem em trabalhos em conjunto. Mas sentimos que nossa experiência reflete uma lição crucial dos Encontros: apesar de levar muito tempo e de ser, muitas vezes, frustrantes, as tentativas de comunicação através de várias divisões são sempre produtivas em algum sentido - quer tal produção se torne real, quer ela permeie a vida e o trabalho das participantes de uma forma menos tangível. 
Além disso, acompanhar os Encontros a partir de nossas locações diferentes permitiunos avaliar uma série de transições na dinâmica, nos discursos e nas práticas do movimento, algo que teria sido difícil, senão impossível, de apreender através de métodos etnográficos com enfoque local apenas. Acreditamos que 'etnografias transnacionais' de eventos como os Encontros podem permitir que as analistas situem melhor os/as atores/actoras e as ações dos movimentos locais e nacionais, dentro de uma estrutura comparativa mais ampla. O tipo de pesquisa etnográfica supralocal que realizamos nesse projeto nos permitiu avaliar as interações dinâmicas entre as diversas actoras que se identificam com o feminismo e observar a formação e as reformulações de alianças, colusões, conflitos e confrontos diretos entre elas. Espaços de movimentos transnacionais também oferecem insights originais sobre o fluxo desigual de poder dentro dos movimentos, particularmente se prestarmos bem atenção a quem fala, quais vozes se tornam hegemônicas, questões e interesses de quem predominam, e quem fica ausente ou é silenciada. Em suma, acompanhar os Encontros regionais e globais do movimento permite às acadêmicas estender a etnografia para além dos limites do local, oferecendo oportunidades únicas de elaborar etnografias da militância transnacional.

Ler os movimentos através de, ou em espaços transnacionais, só faz sentido metodologicamente, contudo, se pudermos basear essas interpretações em etnografias e histórias locais e nacionais. Se não for possível situarmos as diversas participantes dos Encontros em seus contextos locais, existe, obviamente, uma grande probabilidade de fazermos uma leitura errônea do que se fato transpira nos espaços transnacionais do movimento. Uma pesquisa colaborativa entre acadêmicas com conhecimento extenso das diversas localidades serve, portanto, como um corretivo crucial, possibilitando a correção de interpretações individuais em relação àquelas de colegas familiares com os contextos locais/nacionais além daqueles em que foi conduzida a pesquisa. Diante da globalização acelerada e da concomitante intensificação do ativismo transnacional, o tipo de estratégia de pesquisa etnográfica colaborativa a partir de várias localidades (multisited) que realizamos ao analisar os feminismos através das lentes dos Encontros regionais será cada vez mais essencial para uma maior compreensão da dinâmica dos movimentos nos níveis locais e nacionais.

Finalmente, além desse espaço acadêmico de produção de conhecimento, a experiência dos Encontros demonstra o quão imperativo é que as feministas do chamado movimento de mulheres global nutram, mantenham, reinventem e recriem essas formas de espaços produtivos transnacionais do movimento (tanto virtuais como 'reais'), paralelamente a, mas sempre em interação e tensão criativa com, canais intergovernamentais oficiais - tais como a ONU - que também têm sido cruciais para a construção de identidades, discursos e práticas feministas.

\section{Referências bibliográficas}

ABZUG, Bella. "A Global Movement for Democracy." Women's Studies Quarterly, v. 24, n. 12, 1996. p. 117-122.

ALVAREZ, Sonia E. "Latin American Feminisms 'Go Global': Trends of the 1990s and Challenges for the New Millennium." In: ALVAREZ, Sonia E., DAGNINO, Evelina, and ESCOBAR, Arturo (eds.). Cultures of Politics/Politics of Cultures: Re-visioning Latin American Social Movements. Boulder, Colo: Westview, 1998. p. 293-324.

"Advocating Feminism: The Latin American Feminist NGO 'Boom.'” International Feminist Journal of Politics, v. 2, n. 1, 1999. p. 181-209. 
. "Translating the Global: Effects of Transnational Organizing on Latin American Feminist Discourses and Practices." Meridians: A Journal of Feminisms, Race, Transnationalism, v. 1, n. 1, 2000. p. 29-67.

ALVAREZ, Sonia E., LIBARDONI, Marlene, and SOARES, Vera. 2000. "Dossiê Advocacy Feminista [Feminist Advocacy Dossier]," with Marlene Libardoni and Vera Soares. Revista Estudos Feministas, v. 8, n. 2, 2000.

AMADO, Ana Maria. "El neo papismo de Menem." fempress, n. 167 (September), 1995. p. 3. ANCHEITA, Alexandra. Interview by Maylei Blackwell. Tape recording. Offices of K'inal Antsetik, Mexico City, March 15, 1999.

ARDITTI, Rita. Searching for Life: Grandmothers of the Plaza de Mayo and the Disappeared Children of Argentina. Berkeley: University of California Press, 1999.

ASTURIAS, Laura E. "El Presidente y las Conferencias Mundiales." fempress, n. 166 (August), 1995. p. 2.

BARRIG, Maruja. 2001 a. "Latin American Feminisms: Gains, Losses, and Hard Times." NACLA Report on the Americas, n. 34 (MarchApril), 2001a. p. 29-35.

El mundo al reves: Images de la mujer indigena. Buenos Aires: CLASCO, $2001 \mathrm{~b}$.

$\overline{B A S U}$, Amrita. 2000. "Globalization of the Local/Localization of the Global: Mapping Transnational Women's Movements." Meridians, n. 1 (Autumn), 2000. p. 68-84.

BENNETT, Vivienne. 1992. "The Evolution of Urban Popular Movements in Mexico between 1968 and 1988." In: ESCOBAR, Arturo and ESCOBAR, Sonia E. ALVAREZ (eds.). The Making of Social Movements in Latin America: Identity, Strategy, and Democracy. Boulder, Colo.: Westview, 1992. p. 240-259.

BLACKWELL, Maylei. "Geographies of Difference: Mapping Multiple Feminist Insurgencies and Transnational Public Cultures in the Americas." Ph.D. dissertation, University of California, Santa Cruz. 2000.

CALDEIRA, Teresa Pires de Rio. "Women, Daily Life and Politics." In: JELIN, Elizabeth (ed.). Women and Social Change in Latin America. Trans.: J. Ann Zammit and Marilyn Thompson. London: Zed Books, 1990. p. 47-78.

CHEN, Martha Alter. 1996. "Engendering World Conferences: The International Women's Movement and the UN." In: WEISS, Thomas G., and GORDENKER, Leon. NGOs, the UN, and Global Governance. Boulder, Colo.: Rienner, 1996. p. 139-158.

CLARK, Ann Marie, FRIEDMAN, Elisabeth J., and HOCHSTETLER, Kathryn. "The Sovereign Limits of Global Civil Society: A Comparison of NGO Participation in UN World Conferences on the Environment, Human Rights, and Women." World Politics, v. 51, n. 1, 1998. p. 1-35.

COMISIÓN ORGANIZADORA DEL VII ENCUENTRO. 1996. "Convocatoria." Flier.

COTIDIANO MUJER 3. n. 22 (May), 1996. p. 3.

CRASKE, Nikki. "Remasculinisation and the Neoliberal State in Latin America." In: RANDALL, Vicky, and WAYLEN, Georgina (eds.) Gender, Politics, and the State. London: Routledge, 1998. p. 100-120.

Continuing the Challenge: The Contemporary Latin American Women's Movement(s). Research Paper n. 23. University of Liverpool, Institute of Latin American Studies. 2000.

"DECLARACIÓN DE LAS JÓVENES FEMINISTAS." 1999. Flier.

"DESDE 'NI LAS UNAS NI LAS OTRAS' HACIA LAS 'UNAS' Y LAS 'OTRAS.'” In: OLEA MAULEÓN, Cecilia (ed.). Encuentros, (des)encuentros y búsquedas: El movimiento feminista en América Latina. Lima: Ediciones Flora Tristán, 1998. p. 225-228.

DEVELOPMENT ALTERNATIVES WITH WOMEN FOR A NEW ERA (DAWN) and RED DE EDUCACIÓN POPULAR ENTRE MUJERES DE AMÉRICA LATINA Y EL CARIBE (REPEM) (eds.). De poderes y saberes: Debates sobre reestructura política y transformación social, memória del II seminario regional. Montevideo, Uruguay: DAWN, REPEM, 2000. 
DOS SANTOS, Maria Cecília Mac Dowell. "Gender, the State, and Citizenship: Women's Police Stations in São Paulo, Brazil." In: POGGIO, Sara, and SAGOT, Montserrat (eds.). Irrumpiendo en lo público: Seis facetas de las mujeres en América Latina. San José, Costa Rica: Maestría Regional en Estudios de la Mujer, Universidad de Costa Rica; Universidad Nacional, 2000. p. 63-92.

FACCIO, Alda. 1995. "Muchos caminos hacia Beijing." fempress, n. 153 (July), p. 4.

FISHER, Amalia. "Los encuentros feministas: En busca del rumbo perdido o de uno nuevo." In: MOVIMIENTO FEMINISTA AUTÓNOMO (ed.). Reflexiones desde el movimiento feminista autónomo. Santiago: n.p., 1995. p. 27-46.

FITZSIMMONS, Tracy. Beyond the Barricades: Women, Civil Society, and Participation after Democratization in Latin America. New York: Garland, 2000.

FRANCO, Jean. 1998. "Defrocking the Vatican: Feminism's Secular Project." In: ALVAREZ, Sonia E., DAGNINO, Evelina, and ESCOBAR, Arturo (eds.). Cultures of Politics/Politics of Cultures: Re-visioning Latin American Social Movements. Boulder, Colo.: Westview, 1998. p. 278289. 44.

2001. "Bodies in Contention." NACLA Report on the Americas, v. 34, n. 5, 2001. p. 41 -

FRASER, Arvonne S. The UN Decade for Women: Documents and Dialogue. Boulder, Colo.: Westview, 1987.

FRIEDMAN, Elisabeth Jay. "Women's Human Rights: The Emergence of a Movement.” In: PETERS, Julie and WOLPER, Andrea (eds.). Women's Rights, Human Rights: International Feminist Perspectives. New York: Routledge, 1995. p. 18-35.

1999. "The Effects of 'Transnationalism Reversed' in Venezuela: Assessing the Impact of UN Global Conferences on the Women's Movement." International Feminist Journal of Politics, v. 1, n. 3, 1999. p. 57-81.

FRIEDMAN, Elisabeth Jay, HOCHSTETLER, Kathryn, and CLARK, Ann Marie. 2000. "Sovereign Limits and Regional Opportunities for Global Civil Society in Latin America." Latin American Research Review, v. 3, n. 3, 2000. p. 7-36.

FROHMANN, Alicia, and VALDÉS, Teresa. "Democracy in the Country and in the Home: The Women's Movement in Chile." In: BASU, Amrita (ed.). The Challenge of Local Feminisms: Women's Movements in Global Perspective. Boulder, Colo.: Westview, 1995. p. 276-301.

GALVÁN, Sergia. 1995. "El mundo étnico-racial dentro del feminismo Latinoamericano." In: "La mujer negra", special issue of fempress, 34-36.

GARGALLO, Francesca. 1991. 'Los encuentros del desencuentro.' fem, n. 93 (February), 1991. p. 15-16.

GUERRERO, Elizabeth, and RíOS TOBAR, Marcela. "El camino que lleva a la plaza: Delineando el campo de acción feminista hoy." In: RíOS TOBAR, Marcela (ed.). Reflexiones teóricas y comparativas sobre los feminismos en Chile y América Latina. Santiago: Notas del Conversatorio, 1998. p. 23-31.

HTUN, Mala. 1998. "Women's Rights and Opportunities in Latin America: Problems and Prospects." Issue brief for the Women's Leadership Conference of the Americas, InterAmerican Dialogue, Washington, D.C. Available on-line at <http://www.iadialog.org > .

JAQUETTE, Jane S., and WOLCHIK, Sharon L. (eds.). Women and Democracy: Latin America and Central and Eastern Europe. Baltimore: Johns Hopkins University Press, 1998.

JELIN, Elizabeth (ed.). Women and Social Change in Latin America. London: Zed, 1990.

KARDAM, Nuket. 1997. "The Emerging International Women's Regime." Unpublished manuscript, Monterey Institute for International Studies.

KECK, Margaret E., and SIKKINK, Kathryn. Activists beyond Borders: Advocacy Networks in International Politics. Ithaca, N.Y.: Cornell University Press, 1998. 
LEBON, Nathalie.. "The Brazilian Feminist Movement in the Post-constitutional Era: Assessing the Impact of the Rise of Feminist Non-governmental Organizations." Florida Journal of Anthropology, n. 18, 1993. p. 17-26.

"The Labor of Love and Bread: Volunteer and Professionalized Activism in the São Paulo Women's Health Movement." Ph.D. dissertation, University of Florida. 1998.

LIDID, Sandra, and MALDONADO, Kira. "Palabras iniciales." In: MALDONADO, Kira, and LIDID, Sandra (eds.). Movimiento feminista autónomo (19931996). Santiago: Ediciones Número Crítico, 1996. p. 2-4.

LIND, Amy C. "Power, Gender, and Development: Popular Women's Organizations and the Politics of Needs in Ecuador." In: ESCOBAR, Arturo, and ALVAREZ, Sonia (eds.). The Making of Social Movements in Latin America: Identity, Strategy, and Democracy. Boulder, Colo.: Westview, 1992. p. 134-149.

. "Gender, Development and Women's Political Practices in Ecuador." Ph.D. dissertation, Cornell University. 1995.

MANRIQUE, Frida. "Premeiro encuentro feminista Latinoamericano y del Caribe." Mujer y Sociedad, n. 45 (September-October), 1981. p. 2-4.

MASSOLO, Alejandra (ed.). Mujeres y ciudades: Participación social, vivienda y vida cotidiana. México, D.F.: El Colegio de México, 1992.

MELLO, Fatima Vianna. 1994. "Aceptar o no aceptar el dinero? Is That the Question?" fempress, n. 148-149 (February-March), 1994. p. 28-29.

MEYER, Mary K., and PRÜGL, Elisabeth (eds.). Gender Politics in Global Governance. Lanham, Md.: Rowman \& Littlefield, 1999.

MOGROVEJO, Norma.. "Sexual Preference, the Ugly Duckling of Feminist Demands: The Lesbian Movement in Mexico." In: BLACKWOOD, Evelyn, and WIERINGA, Saskia (eds.). Female Desires: Same Sex Relations and Transgender Practices across Cultures. New York: Columbia University Press, 1998. p. 308-335.

. Un amor que se atrevió a decir su nombre: La lucha de las lesbianas y su relación con los movimientos homosexual y feminista en América Latina. México, D.F.: Plaza y Valdés Editores; Centro de Documentación y Archivo Histórico Lésbico "Nancy Cárdenas", 2000.

MOLYNEUX, Maxine. "Twentieth-Century State Formations in Latin America." In: DORE Elizabeth, and MOLYNEUX, Maxine (ed.). Hidden Histories of Gender and the State in Latin America. Durham, N.C.: Duke University Press, 2000. p. 33-84.

MURDOCK, Donna F. Forthcoming. "Localizing the Global: Women's NGOs and Bureaucratic Discipline in Medellin." Dissertation in progress, Emory University. Unpublished manuscript.

NAVARRO, Marysa. "The Personal Is Political: Las madres de la Plaza de Mayo." In: ECKSTEIN, Susan (ed.). Power and Popular Protest: Latin American Social Movements. Berkeley: University of California Press, 1989. p. 242-258.

. 1998. "Una reflexión: Notas sobre uno de los posibles papas del feminismo Latinoamericano para ir creando futuras cartografías." In: OLEA MAULEÓN, Cecilia (ed.) Encuentros, (des)encuentros y búsquedas: El movimiento feminista en América Latina. Lima: Ediciones Flora Tristán, 1998. p. 97-112.

NAVARRO, Marysa, and BOURQUE, Susan C. "Fault Lines of Democratic Governance: A Gender Perspective." In: AGUERO, Felipe, and STARK, Jeffrey (eds.). Fault Lines of Democracy in Post-transition Latin America. Coral Gables, Fla.: North-South Center, 1998. p. 175-202.

NELSON, Sara. "Constructing and Negotiating Gender in Women's Police Stations in Brazil." Latin American Perspectives, v. 23, n. 1, 1996. p. 131-154.

OLEA MAULEÓN, Cecilia (ed.) Encuentros, (des)encuentros y búsquedas: El movimiento feminista en América Latina. Lima: Ediciones Flora Tristán, 1998. 
PORTUGAL, Ana María. "¿Qué es ser feminista en América Latina?" In: ISIS INTERNATIONAL (ed.). Movimiento feminista, balance y perspectivas. Santiago: Ediciones de las Mujeres, 1986.

RÍOS TOBAR, Marcela. "Feminismo(s) Chileno en los noventa: Paradojas de una transición inconclusa." Cuadernos de Investigación Social, n. 9. Lima, Perú: Pontífica Universidad Católica del Perú, Departamento de Ciencias Sociales, 2000.

RíOS TOBAR, Marcela, GODOY, Lorena, and GUERRERO, Elizabeth. "El movimiento de feminista en el Chile: Actores sociales y transición a la democracia." Unpublished manuscript, Centro de Estudios de la Mujer, Santiago, 2002.

RODRÍGUEZ, María Lis. "Agua fria camino a Beijing." fempress, n. 167 (September), 1995. p. 5.

SCHILD, Verónica. "New Subjects of Rights? Women's Movements and the Construction of Citizenship in the 'New Democracies'." In: ALVAREZ, Sonia E., DAGNINO, Evelina, and ESCOBAR Arturo (eds.). Cultures of Politics/Politics of Cultures: Re-visioning Latin American Social Movements. Boulder, Colo.: Westview, 1998. p. 93-117.

SHUMAHER, Maria Aparecida, and VARGAS, Elisabeth. "Lugar en el gobierno: ¿Alibi o conquista?" Debate feminista, n. 15 (April), 1997. p. 128-147.

STEPHEN, Lynn. Women and Social Movements in Latin America: Power from Below. Austin: University of Texas Press, 1997.

. "Gender and Grassroots Organizing: Lessons from Chiapas." In: RODRíGUEZ, Victoria E. (ed.). Women's Participation in Mexican Political Life. Boulder, Colo.: Westview, 1998. p. 146-166.

STEPHENSON, Carolyn M. "Women's International Nongovernmental Organizations at the United Nations." In: WINSLOW, Anne (ed.). Women, Politics, and the United Nations. Westport, Conn.: Greenwood, 1995. p. 134-153.

STERNBACH, Nancy Saporta, NAVARRO-ARANGUREN, Marysa, CHUCHRYK, Patricia, and ALVAREZ, Sonia E. "Feminisms in Latin America: From Bogotá to San Bernardo." Signs: Journal of Women in Culture and Society, v. 17, n. 2, 1992. p. 393-434. [translation: "Feminismo(s) na América Latina: de Bogotá a San Bernardo." Revista Estudos Feministas (Brazil), v. 2, n. 2, 1994.]

STIENSTRA, Deborah. Women's Movements and International Organizations. New York: St. Martin's Press, 1994.

TAMAYO, Giulia. "Derechos humanos de las mujeres, violencia contra la mujer, y paz en la región: Revisión de avances y desafíos a cinco años de la cuarta conferencia mundial sobre la mujer." Informe preparado para la articulación regional sobre la mujer de América Latina y el Caribe, ante la octava conferencia regional sobre la mujer de América Latina y el Caribe. Photocopy. Centro de la Mujer Peruana, Lima, 2000.

TAYLOR, Diana. Disappearing Acts: Spectacles of Gender and Nationalism in Argentina's "Dirty War." Durham, N.C.: Duke University Press, 1997.

VALDÉS, Teresa, and WEINSTEIN, Marisa. "Corriendo y escorriendo tupidos velos." In: Chile 96: Análisis y opiniones. Santiago: FLACSO-Chile, 1997. p. 67-77.

VALENZUELA, María Elena. "Women and the Democratization Process in Chile." In: JAQUETTE, Jane S., and WOLCHIK, Sharon L. (eds.). Women and Democracy: Latin America and Central and Eastern Europe. Baltimore: Johns Hopkins University Press, 1998. p. 47-74.

VARGAS, Virginia. "Disputando el espacio global: El movimiento de mujeres y la IV Conferencia de Beijing." Nueva sociedad, n. 141 (JanuaryFebruary), 1996. p. 43-54.

. "Carta hacia el VII Encuentro Feminista Latinoamericano y del Caribe. Chile, 1996." In: OLEA MAULEÓN, Cecilia (ed.) Encuentros, (des)encuentros y búsquedas: El movimiento feminista en América Latina. Lima: Ediciones Flora Tristán, 1998a. p. 15-38. 
. "Knots in the Region." In: Roads to Beijing: Fourth World Conference on Women in Latin America and the Caribbean. Lima: Ediciones Flora Tristán; Santafé de Bogotá: UNICEF; Quito: UNIFEM, 1998b. p. 1-14.

"Encuentros feministas: Énfasis y estrategias." In: Feminismos plurales: VII Encuentro Feminista Latinoamericano y del Caribe. Aportes para el debate 7 de la Agencia Lationamericana de Información (ALAl) (November), 1999. p. 30-32.

. "Institucionalidad democrática y estrategias feministas en los años 90: El estado, las mujeres y la política a través de la historia Latinoamericana." In: DEVELOPMENT ALTERNATIVES WITH WOMEN FOR A NEW ERA (DAWN) AND RED DE EDUCACIÓN POPULAR ENTRE MUJERES DE AMÉRICA LATINA Y EL CARIBE (REPEM) (eds.). De poderes y saberes: Debates sobre reestructura política y transformación social, memória del II Seminario Regional. Montevideo, Uruguay: DAWN, REPEM, 2000. p. 33-72.

VARGAS, Virginia, and OLEA MAULEÓN, Cecilia. Interview by Sonia E. Alvarez. Centro Flora Tristán and Regional NGO Coordination for Beijing, Lima, Peru, August 19, 1997.

. 1998. "Roads to Beijing: Reflections from Inside the Process." In: Roads to Beijing. p. 15-38.

\section{Encountering Latin American and Caribbean Feminisms}

Abstract: This article examines the Latin American and Caribbean Feminist Encuentros as critical transnational sites for the collective re-imagining of feminist politics in the region. Paying special attention to the most recent regional gathering, held in Juan Dolio, Dominican Republic in 1999, we analyze the major political and philosophical debates that have emerged during twenty years of Encuentros: 1) shifting conceptions of movement "autonomy" and feminisms' relationship to the larger women's movement and to other actors in civil and political society, the State, and international institutions; 2) controversies generated by the movements' recurrent "crises of inclusion" and "crises of expansion"; and 3) debates centered on differences, inequalities, and power imbalances among women, in general, and among feminists, in particular. While this essay explores how the Encuentros have marked feminist debates in the region, it also argues that they are, in themselves, productive transborder sites that not only reflect but also (re)shape Latin American and Caribbean feminist discourses and practices.

Key words: feminist activism, Latin American feminist movements, feminist conferences, transnational feminisms. 